\title{
A zinc finger protein gene ZFP5 integrates phytohormone signaling to control root hair development in Arabidopsis
}

\author{
Lijun An ${ }^{1, \dagger}$, Zhongjing Zhou ${ }^{1, \dagger}$, Lili Sun ${ }^{1}$, An Yan ${ }^{1}$, Wanyan $\mathrm{Xi}^{2}$, Nan $\mathrm{Yu}^{3}$, Wenjuan $\mathrm{Cai}^{3}$, Xiaoya $\mathrm{Chen}^{3}$, Hao $\mathrm{Yu}^{2}$, \\ John Schiefelbein ${ }^{4, *}$ and Yinbo Gan ${ }^{1, *}$ \\ ${ }^{1}$ Department of Agronomy, College of Agriculture and Biotechnology, Zhejiang University, 866 Yuhangtang Rd, Hangzhou \\ 310058, China, \\ ${ }^{2}$ Department of Biological Sciences and Temasek Life Sciences Laboratory, National University of Singapore, 117543 \\ Singapore, \\ ${ }^{3}$ National Key Laboratory of Plant Mol Genetics, Institute of Plant Physiology and Ecology, Chinese Academy of Sciences, \\ 300 Fenglin Road, Shanghai 200032, China, and \\ ${ }^{4}$ Department of Molecular, Cellular, and Developmental Biology, University of Michigan, Ann Arbor, MI 48109, USA
}

\author{
Received 7 December 2011; revised 20 June 2012; accepted 27 June 2012; published online 14 August 2012 \\ *For correspondence (e-mail ygan@zju.edu.cn; schiefel@umich.edu). \\ ${ }^{\dagger}$ These authors contributed equally to this work.
}

\begin{abstract}
SUMMARY
Although root hair development in Arabidopsis thaliana has been extensively studied, it remains unknown whether the zinc finger proteins, the largest family of transcription factors in plants, are involved in this process. Here we report that the $\mathrm{C} 2 \mathrm{H} 2$ zinc finger protein ZINC FINGER PROTEIN 5 (ZFP5) is a key regulator of root hair initiation and morphogenesis in Arabidopsis. ZFP5 is mainly expressed in root and preferentially in root hair cells. Using both zfp5 mutants and ZFP5 RNAi lines, we show that reduction in ZFP5 function leads to fewer and much shorter root hairs compared to wild-type. Genetic and molecular experiments demonstrate that ZFP5 exerts its effect on root hair development by directly promoting expression of the CAPRICE (CPC) gene. Furthermore, we show that ZFP5 expression is induced by cytokinin, and that ZFP5 mediates cytokinin and ethylene effects on the formation and growth of root hairs. These results suggest that ZFP5 integrates various plant hormone cues to control root epidermal cell development in Arabidopsis.
\end{abstract}

Keywords: ZFP5, root hair development, cytokinin, $\mathrm{C} 2 \mathrm{H} 2$ zinc finger protein, ethylene, epidermal cell.

\section{INTRODUCTION}

In plants, root hairs are important for the uptake of nutrients and water from the rhizosphere, and serve as sites of interaction with soil micro-organisms and for anchorage of plants in soil (Gilroy and Jones, 2000; Jones et al., 2009). In addition, root hair formation provides a simple and an elegant model for studying cell fate and cell morphogenesis because of their predictable pattern, polar growth, and ease of analysis (Ishida et al., 2008).

In Arabidopsis thaliana, the root epidermis contains alternate files of hair $(\mathrm{H})$ and non-hair $(\mathrm{N})$ cells. Epidermal cells overlying two cortical cells eventually develop into root hairs, while those overlying only one cortical cell develop into mature non-root hair cells (Schiefelbein et al., 2009). This patterning process uses an evolutionarily conserved cassette consisting of MYB, bHLH and homeodomain transcription factors, including GLABRA3 (GL3)/ENHANCER OF GLABRA3 (EGL3), TRANSPARENT TESTA GLABRA
(TTG), CAPRICE (CPC), TRIPTYCHON (TRY), ENHANCER OF TRY AND CPC (ETC.), WEREWOLF (WER) and GLABRA2 (GL2). According to current models, TTG1, GL2 and WER function as negative regulators for root hair cell fate, as mutations in TTG1, GL2 and WER promote conversion of the $\mathrm{N}$ cells to $\mathrm{H}$ cells (Galway et al., 1994; Masucci et al., 1996; Lee and Schiefelbein, 1999). GL3 and EGL3 also act in a redundant manner to determinate the non-hair cell fate (Bernhardt et al., 2003), as the number of root hairs in both $\mathrm{g} / 3$ and $e g / 3$ mutants is increased, and the eg/3 g/3 double mutant shows an ectopic hair phenotype (Bernhardt et al., 2003). CPC, a small R3-type MYB transcription factor, is a positive regulator of root hair cell determination (Wada et al., 1997), as mutations in CPC result in only a few root hairs being produced (Wada et al., 2002; Tominaga et al., 2008). TRY and ETC. are homologous genes of CPC, and their products act redundantly with $\mathrm{CPC}$ to positively 
regulate root hair formation (Schellmann et al., 2002; Esch et al., 2004; Kirik et al., 2004a; b; Simon et al., 2007; Tominaga et al., 2008). The $c p c$ try and $c p c$ etc 1 double mutants produce very few hair cells (Schellmann et al., 2002; Kirik et al., 2004b; Tominaga et al., 2008), and over-expressing CPC, TRY or ETC1 under the control of the CaMV $35 \mathrm{~S}$ promoter produces more root hairs compared to the wildtype (Schellmann et al., 2002; Kirik et al., 2004b; Tominaga et al., 2008). It is thought that a WER-GL3/EGL3-TTG1 complex preferentially accumulates in $\mathrm{N}$ cell files and acts upstream of $\mathrm{GL2}$, which is required for $\mathrm{N}$ cell differentiation (Costa and Shaw, 2006; Ishida et al., 2008; Schiefelbein et al., 2009; Tominaga-Wada et al., 2011). The CPC gene is preferentially transcribed in $\mathrm{N}$ cells, but its protein product can move to the neighboring $\mathrm{H}$ cells where it competes against WER for binding to the GL3/EGL3-TTG complex (Schellmann et al., 2002; Pesch and Hülskamp, 2004; Kurata et al., 2005; Simon et al., 2007). Binding of CPC to the GL3/ EGL3-TTG complex inhibits GL2 expression, resulting in $\mathrm{H}$ cell specification. In addition, GL3/EGL3 can also move from $\mathrm{H}$ cells to $\mathrm{N}$ cells to participate in communication between the $\mathrm{N}$ and $\mathrm{H}$ cells to reinforce the cell specificity (Bernhardt et al., 2005; Schiefelbein and Lee, 2006).

After cell fate determination, the developing hair cells (or trichoblasts) begin to establish cell polarity and root hair tip growth, ultimately forming tubular-shaped hairs. Many molecules, including ions, are involved in this complicated process (Tominaga-Wada et al., 2011). Ionic influx is necessary for root hair tip growth, and some mutants possessing short root hairs are ion uptake-deficient. For example, the root hair deficient 2 (rhd2) mutant possesses bulges of the correct size and location, but cannot proceed with hair elongation (Schiefelbein and Somerville, 1990). Interestingly, $\mathrm{Ca}^{2+}$ gradients are not observed in swellings on most $\mathrm{H}$ cells of the mutants (Wymer et al., 1997), suggesting that $R H D 2$ plays an important role in $\mathrm{Ca}^{2+}$ uptake by root hair cells, and subsequent research indicated a positive feedback mechanism involving $R H D 2$, reactive oxygen species and $\mathrm{Ca}^{2+}$ in determination of cell shape (Takeda et al., 2008). $\mathrm{K}^{+}$translocation is also indispensable for root hair elongation. TINY ROOT HAIR 1 (TRH1) is a member of the Arabidopsis thaliana $\mathrm{K}^{+}$Transport (AtKT) Arabidopsis thaliana $\mathrm{K}^{+}$Uptake Transporter (AtKUP)/Arabidopsis thaliana High-Affinity $\mathrm{K}^{+}$Transporter (AtHAK) family of potassium carriers (Kim et al., 1998), and mediates $\mathrm{K}^{+}$transport in roots (Desbrosses et al., 2003). The trh1-1 mutant forms short root hairs (Rigas et al., 2001), and the trh 1-1 phenotype cannot be suppressed by application of a high concentration of external $\mathrm{KCl}$, indicating an absolute requirement for $T R H 1$ in root hair tip growth (Desbrosses et al., 2003). The materials required for cell-wall synthesis are indispensable for root hair elongation. $R H D 1$ is one of five widely expressed family genes that encode UDP-D-glucose-4-epimerase (UGE4), which acts in formation of UDP-D-galactose (Seifert et al., 2002). The rhd1 mutant has short root hairs and bulges (Schiefelbein and Somerville, 1990; Seifert et al., 2002) due to a lack of arabinosylated (1,6)- $\beta$-D-galactan and galactosylated xyloglucan (Seifert et al., 2002).

Plant hormones and environmental signals are also considered to be important regulators of root hair development (Bucio et al., 2003; Guimil and Dunand, 2006; Ishida et al., 2008; Yi et al., 2010). It is well known that ethylene decreases root cell length and increases root width and root hair length (Tanimoto et al., 1995). Endogenous ethylene directs auxin to control root cell expansion (Strader et al., 2010), and auxin plays important roles in regulating root hair formation when ethylene transduction signals are inhibited (Rahman et al., 2002). Moreover, these two hormones act together with environmental signals to contribute to root hair development. In the case of potassium stress, ethylene plays important roles in regulating the formation of root hairs and the main root by producing reactive oxygen species, and auxin regulates the root structure by regulating phosphate levels (Schmidt and Schikora, 2001; López-Bucio et al., 2002; Jung et al., 2009). In addition, low nutrition stress can also affect root hair development by interacting with transcription factors. It has been shown that the $c p c$ mutant produces as many root hairs as wild-type roots when grown in an iron- and phosphate-deficient medium (Müller and Schmidt, 2004). Furthermore, ROOT HAIR DEFECTIVE 6-LIKE 4 (RSL4), a basic helix-loop-helix (bHLH) transcription factor, integrates endogenous developmental and exogenous environmental signals to control postmitotic growth in root hairs (Yi et al., 2010). It is notable that cytokinins, plant-specific hormones that influence the cell cycle and numerous developmental programs (Werner and Schmülling, 2009; Bishopp et al., 2011; Kushwah et al., 2011; Muraro et al., 2011; Zhang et al., 2011), have not yet been clearly implicated in root hair development.

In this paper, we report identification of a putative $\mathrm{C} 2 \mathrm{H} 2$ zinc finger transcription factor, ZFP5, that modulates root hair initiation and elongation by cytokinin and ethylene signals. Molecular and genetic analyses show that ZFP5 controls root hair initiation by directly targeting CPC, providing a new insight into the mechanisms of cell differentiation in this model system.

\section{RESULTS}

\section{ZFP5 acts as a positive regulator of root hair development in Arabidopsis}

To test whether the ZFP5 gene is involved in mediating root hair development, we analyzed a previously identified T-DNA insertion mutant from the Nottingham Arabidopsis Stock Centre, in which the promoter of ZFP5 is interrupted by a T-DNA insertion. The presence of the T-DNA was verified by genomic PCR as described previously (Zhou et al., 2011), and ZFP5 expression in the mutant was determined 
by quantitative real-time PCR analysis as described previously (Zhou et al., 2011). The zfp5-4 mutant has much shorter and fewer root hairs than the wild-type (Figure 1a,b,e). To verify the phenotype of the zfp5-4 loss-offunction mutant, we analyzed previously generated multiple ZFP5 RNAi transgenic lines, and ZFP5 expression levels were determined to confirm that transcription was inhibited as previously reported (Zhou et al., 2011). ZFP5 RNAi lines had a similar phenotype to that of the T-DNA insertion mutant (Figure 1c,e). We next analyzed the formation of root hair cells in $\mathrm{H}$ cell and $\mathrm{N}$ cell positions, and found that the percentage of root hair cells in the epidermis (root hair density) in both the zfp5-4 mutant and ZFP5 RNAi plants was significantly reduced in comparison with wild-type plants (Table 1). Further investigation indicated that the hair cell percentage in $\mathrm{H}$ cell positions in both zfp5-4 mutant and ZFP5 RNAi plants was significantly suppressed (Table 1).
To further verify that the phenotype was caused by the zfp5-4 loss-of-function mutation and not by another linked mutation, we over-expressed ZFP5 in the zfp5-4 background using the CaMV $35 \mathrm{~S}$ promoter. We discovered that over-expression can restore the shorter root hair phenotype of the mutant (Figure 1d,e) as well as the numbers of root hair cells in the $\mathrm{H}$ cell position to the wild-type level (Table 1).

To further define the zfp5-4 mutant shorter root hair phenotype, we compared root hair growth rates between wild-type plants and the mutant using time-lapse microscopy, as described by Szumlanski and Nielsen (2009). The growth rate of root hairs in the mutant was significantly lower than that in the wild-type (Figure 2a-f). This result confirmed that the short length of root hairs in the mutant was caused by a reduced rate of root hair elongation, rather than a reduced period of hair growth.
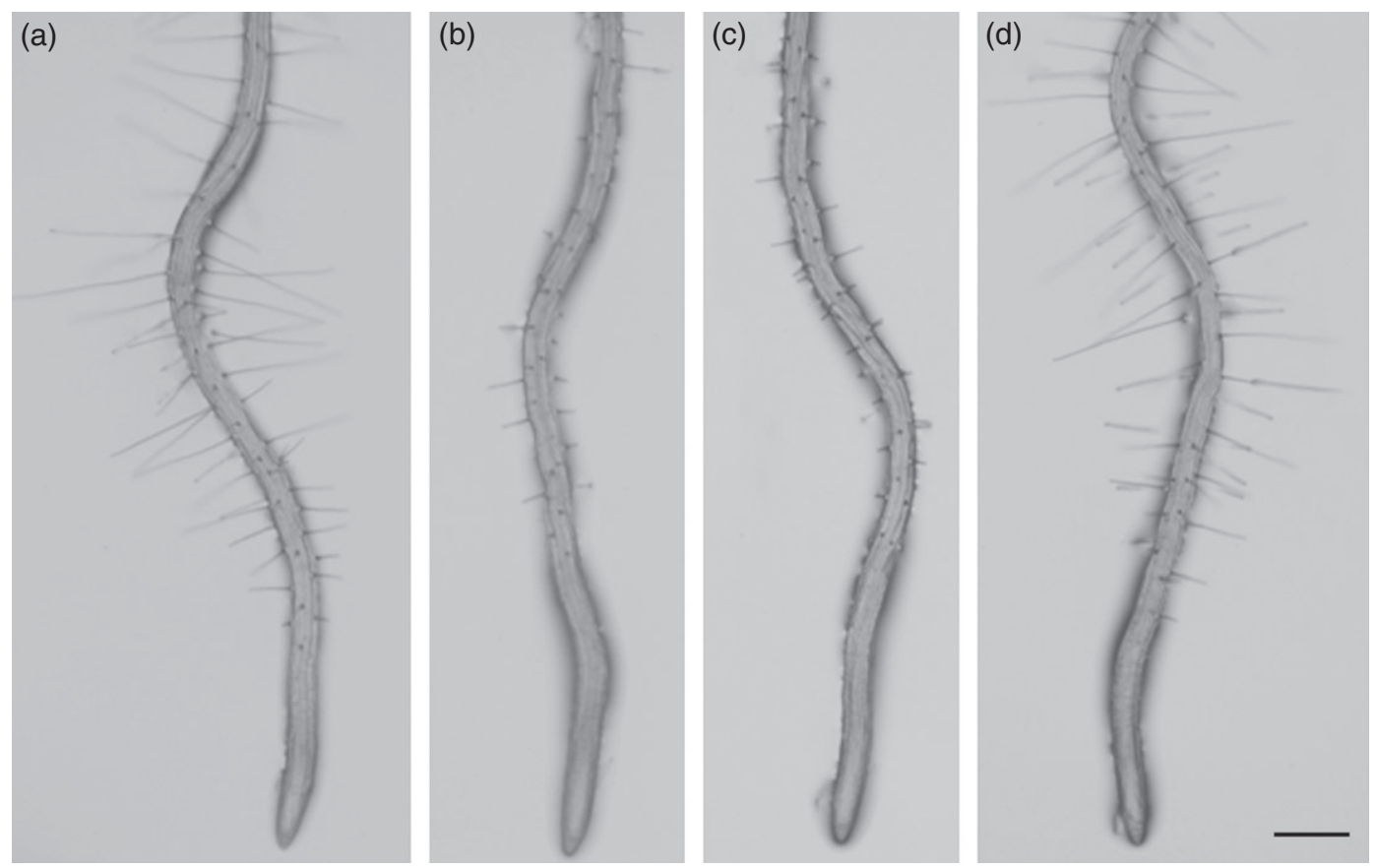

(e)

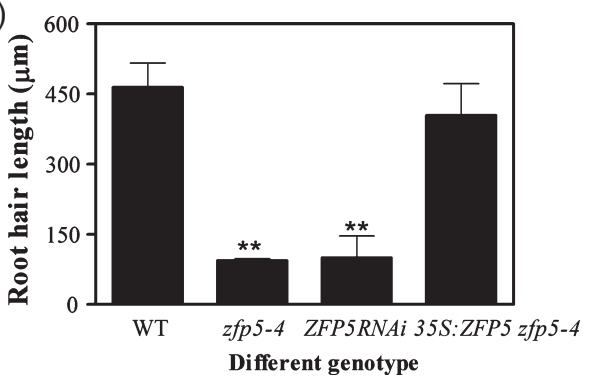

Figure 1. Phenotypes of the loss-of-function zfp5-4 mutant, ZFP5 RNAi line and the ZFP5 over-expressing line.

(a-d) Phenotypes of root hairs of the wild-type (a), zfp5-4 (b), a transgenic plant in which ZFP5 has been silenced by RNAi (c), and the 35S:ZFP5zfp5-4 line (d). Scale bar $=200 \mu \mathrm{m}$.

(e) Mean root hair length for the wild-type, zfp5-4 mutant, ZFP5 RNAi and 35S: ZFP5zfp5-4 transgenic lines. Values are means \pm standard deviations for at least 20 seedlings. ${ }^{*} \mathrm{P}<0.01$ for comparison with wild-type. 
Table 1 Root hair production and root hair and non-hair cell specification in the root epidermis in various genotypes

\begin{tabular}{lllllll}
\hline & & \multicolumn{2}{l}{$H$ cell position } & & & N cell position \\
Genotype & Hair cells in epidermis (\%) & Hair cells (\%) & Non-hair cells (\%) & & Hair cells (\%) & Non-hair cells (\%) \\
\hline Wild-type (Col-0) & $42.3 \pm 8.7$ & $90.0 \pm 4.0$ & $10.0 \pm 4.0$ & & $5.0 \pm 3.5$ & $95.0 \pm 3.5$ \\
zfp5-4 & $31.0 \pm 8.5^{* *}$ & $75.0 \pm 1.5^{* *}$ & $25.0 \pm 1.5^{* *}$ & & $3.0 \pm 7.3$ & $97.0 \pm 7.3$ \\
ZFP5 RNAi & $31.4 \pm 8.2^{* *}$ & $77.6 \pm 2.1^{* *}$ & $22.4 \pm 2.1^{* *}$ & & $2.6 \pm 7.5$ & $97.4 \pm 7.5$ \\
35Spro:ZFP5zfp5-4 & $42.6 \pm 5.6$ & $92.5 \pm 10.0$ & $7.5 \pm 10.0$ & & $3.7 \pm 8.1$ & $96.3 \pm 8.1$ \\
35Spro:CKX2 & $31.4 \pm 11.1^{* *}$ & $82.5 \pm 2.7^{* *}$ & $17.5 \pm 2.7^{* *}$ & & $2.2 \pm 6.3$ & $97.8 \pm 6.3$ \\
cpc & $8.6 \pm 3.9^{* *}$ & $11.1 \pm 1.2^{* *}$ & $88.9 \pm 1.2^{* *}$ & & $1.1 \pm 4.7$ & $98.9 \pm 4.7$ \\
cpc zfp5-4 & $6.0 \pm 1.5^{* *}$ & $7.5 \pm 1.0^{* *}$ & $92.5 \pm 1.0^{* *}$ & & $0.0 \pm 0.0^{*}$ & $100.0 \pm 0.0^{*}$ \\
\hline
\end{tabular}

Values indicate mean \pm standard deviation for at least ten roots for each line. In all strains, approximately $40 \%$ of epidermal cells are in the $\mathrm{H}$ position. The least significant differences (LSD) method was used to determine significant differences between genotypes $\left({ }^{*} P<0.05 ;{ }^{*} P<0.01\right)$.
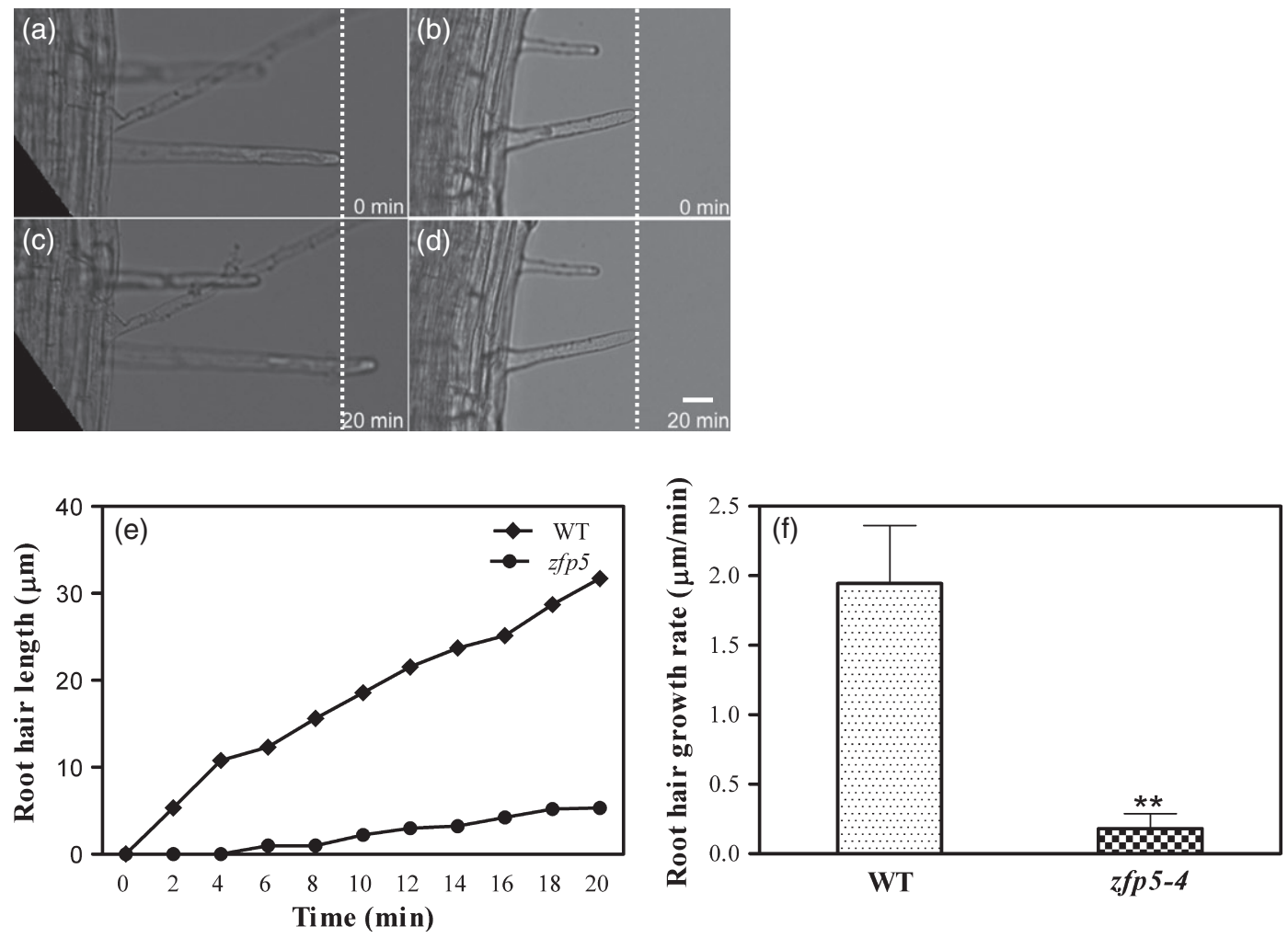

Figure 2. Root hair cell growth rates for wild-type and mutant.

(a-d) Determination of the root hair growth rate of the wild-type $(a, c)$ and the zfp5-4 mutant (b,d) during a 20 min growth period by time-lapse microscopy. Scale bar $=3 \mu \mathrm{m}$.

(e) Typical root hair growth curve for the wild-type and zfp5-4 mutant.

(f) Mean root hair growth rate for the wild-type and zfp5-4 mutant. Values are means \pm standard deviations $(n=3)$. The growth rate for the zfp5-4 mutant was significantly different from that of the wild-type $(* * P<0.01)$.

\section{ZFP5 is required for cytokinin and ethylene signals to control root hair development}

The root hair phenotypes of the zfp5-4 loss-of-function mutant and RNAi plants suggest that ZFP5 acts as a positive regulator to regulate the development of root hairs. As reported previously that ZFP5 controls trichome initiation through gibberellin acid signaling (Zhou et al., 2011) and that its homologous GLABROUS INFLORESCENCE STEMS
(GIS) family genes GIS2 and ZFP8 control trichome cell differentiation through gibberellin acid and cytokinin signaling (Gan et al., 2006, 2007), we investigated whether ZFP5 controls root hair development through plant hormone signaling. The zfp5-4 mutant was treated with various levels of benzylaminopurine (BA) and 1-aminocyclopropane1-carboxylic acid (ACC), which represent cytokinin and ethylene treatments, respectively. The ACC treatment significantly increased the root hair density (Figure 3a-d and 

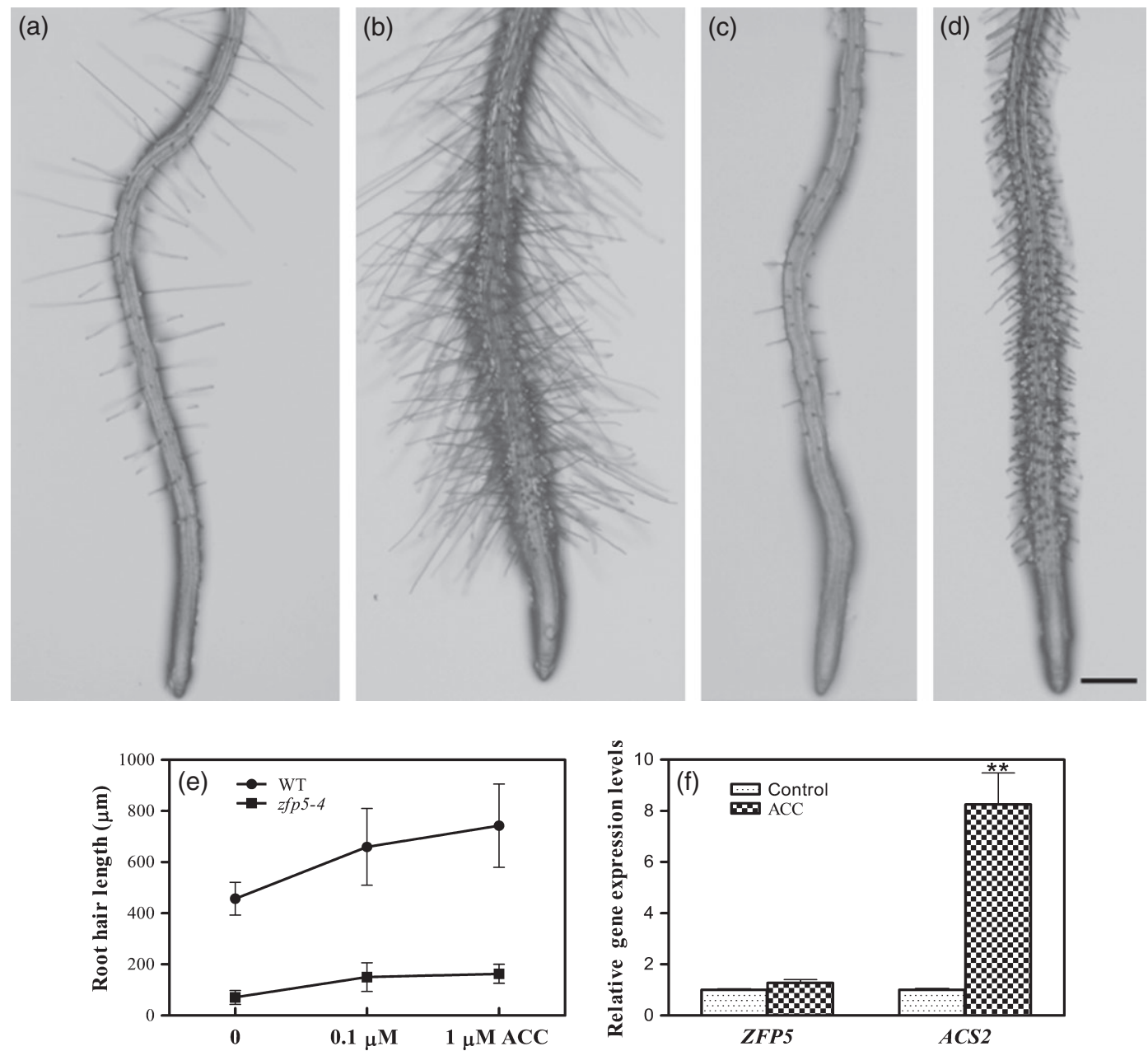

Figure 3. Effects of ethylene application on the zfp5-4 mutant.

$(\mathrm{a}, \mathrm{c})$ Root hair phenotypes of the wild-type (a) and the zfp5-4 mutant (c) grown on normal MS medium.

(b,d) Root hair phenotypes of the wild-type (b) and the zfp5-4 mutant (d) treated with $1 \mu \mathrm{M} \mathrm{ACC.}$

Scale bar $=200 \mu \mathrm{m}(\mathrm{a}-\mathrm{d})$.

(e) Mean hair length of the wild-type and the zfp5-4 mutant treated with ACC. Values are means \pm standard deviations for at least 20 seedlings.

(f) Expression levels of ZFP5 in roots treated with $1 \mu \mathrm{m} \mathrm{ACC}$. The primary regulator gene ACS2 was used as a control. Values are means \pm standard deviations $(n=3$ ).

* $\mathrm{P}<0.01$ for comparison with the control treatment.

Table 2), but not the root hair length of the zfp5-4 mutant (Figure 3e). BA treatment restored the root hair density of zfp5-4 to the wild-type level (Figure $4 a-d$ and Table 2); however, unlike wild-type plants, the root hair length of the zfp5-4 mutant was insensitive to cytokinin application (Figure 4e), indicating that ZFP5 is required for cytokinin and ethylene signaling to control root hair development.

To extend these results, we investigated the expression of ZFP5 in response to external cytokinin and ethylene application. We first characterized the transcription levels of ZFP5 in BA-treated plants and 35S:CKX2 transgenic plants, which are designated to mimic the cytokinin-inhibiting treatment, because $C K X 2$ is one of the cytokinin oxidase genes that inhibit cytokinin synthesis (Gan et al., 2007; Werner and Schmülling, 2009). The results showed that BA treatment significantly induced ZFP5 transcript levels by approximately two fold (Figure 4f). In contrast, ZFP5 expression was significantly decreased in 35S:CKX2 transgenic plants (Figure 4j). Consistent with this, the root hair length and root hair numbers were significantly reduced in 35S:CKX2 plants in comparison to the wild-type (Figure $4 \mathrm{~g}-\mathrm{i}$ and Table 1). In addition, we used ZFP5:GUS transgenic plants to detect whether ZFP5 responds to cytokinin signaling at the protein level. Histochemical staining for GUS activity in ZFP5:GUS plants was significantly enhanced after cytokinin treatment (Figure 4k-m), indicating that cytokinin can induce ZFP5 expression at the protein level.

We also examined the transcript levels of ZFP5 after ACC treatment. ZFP5 transcript accumulation was not significantly changed in response to $A C C$, although expression of an $A C C$ 
Table 2 Root hair production and root hair and non-hair cell specification in the root epidermis of wild-type and zfp5-4 mutant plants grown on control medium and medium containing BA and ACC

\begin{tabular}{|c|c|c|c|c|c|}
\hline \multirow[b]{2}{*}{ Genotype/treatment } & \multirow{2}{*}{$\begin{array}{l}\text { Hair cells in } \\
\text { epidermis(\%) }\end{array}$} & \multicolumn{2}{|l|}{$\mathrm{H}$ cell position } & \multicolumn{2}{|l|}{$\mathrm{N}$ cell position } \\
\hline & & Hair cells (\%) & Non-hair cells (\%) & Hair cells (\%) & Non-hair cells $(\%)$ \\
\hline Wild-type/mock & $42.0 \pm 6.4$ & $95.3 \pm 8.7$ & $4.7 \pm 8.7$ & $1.1 \pm 4.7$ & $98.9 \pm 4.7$ \\
\hline Wild-type/10 nм BA & $50.2 \pm 4.7^{* *}$ & $100.0 \pm 0.0^{*}$ & $0.0 \pm 0.0 *$ & $2.2 \pm 9.4$ & $97.8 \pm 9.4$ \\
\hline Wild-type/100 nм BA & $52.6 \pm 4.5^{* *}$ & $100.0 \pm 0.0^{*}$ & $0.0 \pm 0.0^{*}$ & $2.2 \pm 6.5$ & $97.8 \pm 6.5$ \\
\hline Wild-type/mock & $38.0 \pm 3.3$ & $94.4 \pm 11.5$ & $5.6 \pm 11.5$ & $2.2 \pm 6.5$ & $97.3 \pm 6.5$ \\
\hline Wild-type/100 пм ACC & $68.3 \pm 9.4^{* *}$ & $100.0 \pm 0.0^{*}$ & $0.0 \pm 0.0^{*}$ & $17.8 \pm 15.6^{*}$ & $82.2 \pm 15.6^{*}$ \\
\hline Wild-type/1 $\mu \mathrm{M}$ ACC & $73.0 \pm 8.0^{* *}$ & $100.0 \pm 0.0^{*}$ & $0.0 \pm 0.0^{*}$ & $41.1 \pm 17.2^{* *}$ & $58.9 \pm 17.2^{* *}$ \\
\hline zfp5-4/mock & $33.0 \pm 8.0$ & $78.3 \pm 2.4$ & $21.7 \pm 2.4$ & $0.0 \pm 0.0$ & $100.0 \pm 0.0$ \\
\hline zfp5-4/10 пм ВA & $50.7 \pm 4.7^{* *}$ & $90.0 \pm 2.8$ & $10.0 \pm 2.8$ & $0.0 \pm 0.0$ & $100.0 \pm 0.0$ \\
\hline zfp5-4/100 пм BA & $54.0 \pm 8.2^{* *}$ & $98.0 \pm 2.8$ & $2.0 \pm 2.8$ & $18.0 \pm 2.8^{* *}$ & $82.0 \pm 2.8^{* *}$ \\
\hline zfp5-4/mock & $29.5 \pm 6.1$ & $73.8 \pm 2.2$ & $26.2 \pm 2.2$ & $0.0 \pm 0.0$ & $100.0 \pm 0.0$ \\
\hline zfp5-4/100 пм АCC & $65.2 \pm 5.6^{* *}$ & $98.6 \pm 2.0$ & $1.4 \pm 2.0$ & $34.3 \pm 12.1^{* *}$ & $65.7 \pm 12.1^{* *}$ \\
\hline zfp5-4/1 $\mu \mathrm{M} \mathrm{ACC}$ & $66.4 \pm 8.3^{* *}$ & $100.0 \pm 0.0$ & $0.0 \pm 0.0$ & $42.0 \pm 14.1^{* *}$ & $58.0 \pm 14.1^{* *}$ \\
\hline
\end{tabular}

Values indicate mean \pm standard deviation for at least ten roots for each line. In all strains, approximately $40 \%$ of epidermal cells are in the $\mathrm{H}$ position. The least significant differences (LSD) method was used to determine significant differences compared with mock-treated plants $\left({ }^{*} P<0.05 ;{ }^{*} P<0.01\right)$.

response gene ACS2 was sharply induced (Figure 3f). To further assess the response of ZFP5 expression to ethylene signaling in regulating root hair development, we first investigated the root hair phenotype of the wild-type and zfp5-4 mutants after treatment with aminoethoxyvinylglycine (AVG), either alone or together with ACC treatment. AVG acts as an inhibitor during ethylene biosynthesis. As shown in Figure 5(a-f), AVG treatment significantly inhibited root hair formation and root hair growth in both wild-type and zfp5-4 plants. Moreover, the mutant was more sensitive to AVG treatment, with $2 \mu \mathrm{M}$ almost completely blocking root hair formation in the mutant plants (Figure $5 \mathrm{~g}, \mathrm{~h}$ ). Similar results were observed when AVG was applied together with ACC (Figure 5i-p). These results indicate that ZFP5 expression may be responsive to ethylene in controlling root hair development. To further examine this hypothesis, we assessed ZFP5 expression in ethylene mutants. The results showed that ZFP5 transcripts were reduced in etr1-1, etr1-3 and etr2 mutants, and induced in the eto2 mutant (Figure $5 q$ ). Both GUS staining and Western blotting experiments showed that ZFP5 expression was induced at the protein level (Figure $5 r-u$ ).

Taken together, these results suggest that ZFP5 regulates root hair formation and elongation by mediating both cytokinin and ethylene signaling.

\section{ZFP5 acts upstream of the root hair initiation regulator CPC}

As both root hair length and root hair initiation were affected in the zfp5-4 mutant and ZFP5 RNAi lines, we investigated the interaction between ZFP5 and the known root hair development regulatory pathway, and attempted to identify the direct target(s) of ZFP5. We first measured the expression level of the genes ROOT HAIR LESS 1 (RHL1), GL3, EGL3, TTG1, CPC, TRY and ETC1, which encode the com- ponents of the root hair initiation complexes GL3/EGL3TTG1 and CPC-TRY-ETC1, by quantitative RT-PCR. As shown in Figure 6, expression of CPC was most significantly suppressed in the mutant, and expression of RHL1 and EGL3 was also significantly suppressed. By contrast, expression of GL2, TRY and ETC1 was significantly up-regulated, suggesting that ZFP5 may act upstream of CPC, EGL3 and RHL 1 .

To further confirm whether ZFP5 acts upstream of CPC, we studied the genetic relationship between $Z F P 5$ and $C P C$. First, we over-expressed ZFP5 in the $c p c$ mutant background, and found that the root hair-deficient phenotype of the $c p c$ mutant was not rescued by ZFP5 over-expression (Figure 7a-d). Next, we over-expressed CPC in the zfp5-4 mutant background, and this caused the root hair phenotype of $z f p 5-4$ to be restored to the wild-type level (Figure 7e,g), indicating that ZFP5 acts upstream of CPC to control root hair initiation. In addition, we constructed a cpc zfp5-4 double mutant, and the phenotype of $c p c$ zfp5-4 was similar to that of the $c p c$ mutant (Figure 7f,g and Table 1). We also crossed the zfp5-4 mutant with a CPC:GUS transgenic line to investigate whether the ZFP5 mutation altered the CPC expression pattern. As shown in Figure 8(a-d), GUS signals were confused in CPC:GUSzfp5-4 root epidermis compared to CPC:GUS root epidermis. GUS signals were not only found in hair cells, but also in the adjacent cells. These results further indicate that ZFP5 acts upstream of CPC.

\section{ZFP5 directly targets the CPC promoter to promote root hair development}

To investigate whether ZFP5 promotes root hair formation by directly regulating expression of $C P C$, we investigated whether ZFP5 activates expression of CPC by using 35S:ZFP5:GR transgenic lines in the zfp5-4 mutant background, in which ZFP5 transcription may be instantaneously 

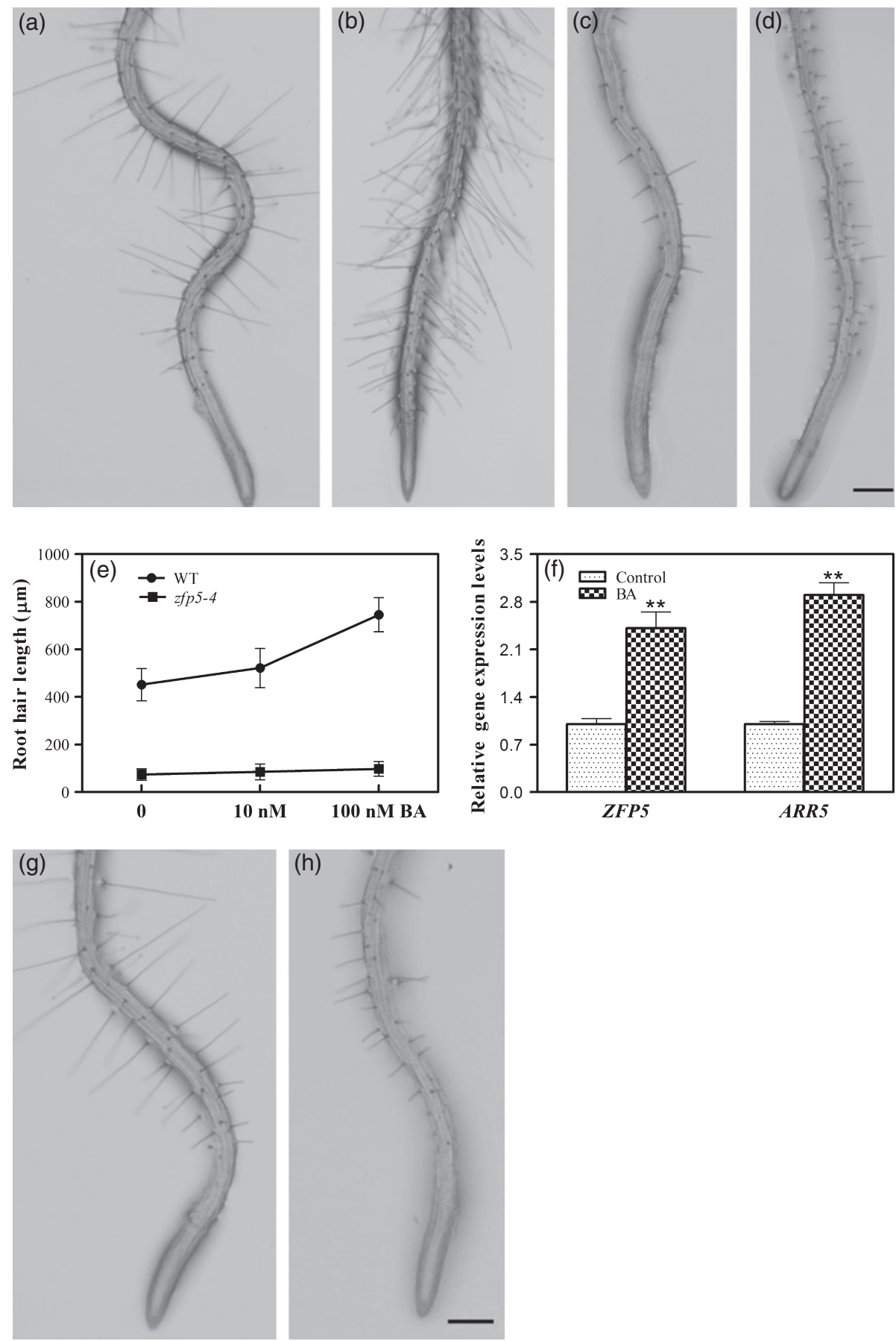

Figure 4. Effects of cytokinin application on the zfp5-4 mutant.

$(a, c)$ Root hair phenotypes of the wild-type (a) and the zfp5-4 mutant (c) grown on normal MS medium.

(b,d) Root hair phenotypes of the wild-type (b) and the zfp5-4 mutant (d) treated with $100 \mathrm{~nm} \mathrm{BA}$

Scale bar $=200 \mu \mathrm{m}(\mathrm{a}-\mathrm{d})$.

(e) Mean root hair length of the wild-type and the zfp5-4 mutant treated with BA. Values are means \pm standard deviations for at least 20 seedlings.

(f) Expression levels of ZFP5 in roots treated with $100 \mathrm{nM} \mathrm{BA}$. The primary regulator ARR5 was used as a control. Values are means \pm standard deviations ( $n=3$ ). ** $P<0.01$ for comparison with no treatment.

$(\mathrm{g}, \mathrm{h})$ Root hair phenotypes of the wild-type $(\mathrm{g})$ and 35S:CKX2 transgenic plants $(\mathrm{h})$. Scale bar $=200 \mu \mathrm{m}$

(i) Mean root hair length of wild-type, zfp5-4 mutant and $35 S: C K X 2$ transgenic plants. Values are means \pm standard deviations for at least 20 seedlings. ${ }^{*} P<0.01$ for comparison with wild-type.

(j) ZFP5 expression level in 35S:CKX2 transgenic plants. Values are means \pm standard deviations $(n=3) .{ }^{*} P<0.01$ for comparison with ZFP5 expression levels in wild-type.

(k-m) Histochemical staining for GUS activity in ZFP5:GUS transgenic plants after exogenous BA treatment: (k) control, (I) $10 \mathrm{~nm}$ BA, (m) $100 \mathrm{~nm}$ BA. Scale bar $=25 \mu \mathrm{m}$ 

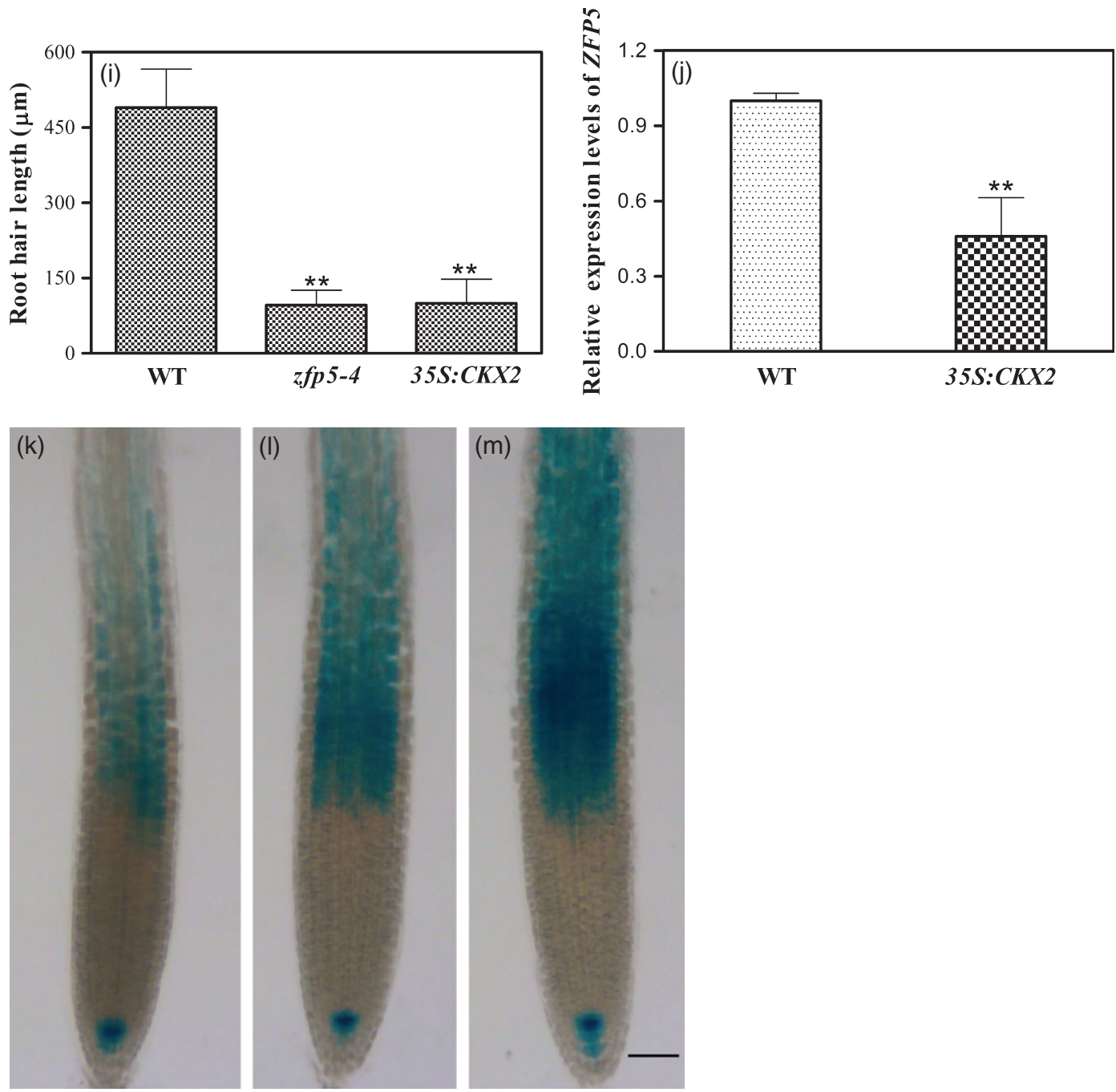

Figure 4. (Continued)

induced by exogenous application of dexamethasone (DEX) (Samalova et al., 2005). As ZFP5 may also act upstream of EGL3 and $R H L 1$, we also investigated whether ZFP5 directly targets $E G L 3$ or RHL 1 to control root hair development. The results show that DEX treatment of 7-day-old 35S:ZFP5:GR zfp5-4 seedling roots caused a significant increase in expression of EGL3,CPC and RHL1, which suggests that ZFP5 rapidly activates transcription of EGL3,CPC and RHL1 (Figure 9a). To further test whether EGL3, CPC and RHL1 are direct targets of ZFP5, we used DEX plus cycloheximide $(\mathrm{CHX})$, a translation inhibitor, and found that the CPC transcript was significantly induced by DEX + CHX treatment, but EGL3 and RHL1 transcripts were not significantly induced (Figure 9a). These results suggest that CPC is a direct target of ZFP5 in promotion of root hair initiation.

To further confirm that ZFP5 directly interacts with CPC, we performed a chromatin immunoprecipitation (ChIP) assay using 35S:ZFP5:GFP transgenic plants. We scanned a $2 \mathrm{~kb} C P C$ promoter region for sequences similar to the conserved sequence $A[A G / C T] C N A C$, which is the binding site of target genes for $\mathrm{C} 2 \mathrm{H} 2$ zinc finger proteins (Sakai et al., 1995; Kubo et al., 1998). We found two possible binding sequences: AAGTCTTT, located at -1032 to $-1024 \mathrm{bp}$, and AAGTCAAA, located at -347 to $-339 \mathrm{bp}$. These were designated as region I and region II, respectively (Figure 9a). We also discovered two $\mathrm{CpG}$-enriched fragments, located at -1500 to $-1270 \mathrm{bp}$ and -750 to $-540 \mathrm{bp}$, designated as region III and IV, respectively (Figure $9 \mathrm{~b}$ ). The results of the ChIP assay showed that fragments I and II were enriched with GFP antibody (Figure 9c). These data further indicate that ZFP5 directly targets CPC to control root hair initiation.

\section{ZFP5 is highly expressed in root and hair cells}

As reported previously, ZFP5 is mainly expressed in the root (Zhou et al., 2011). Using ZFP5:GUS transgenic plants, we detected GUS activity primarily in the root (Figure 10a). We further investigated the ZFP5 expression pattern by in situ hybridization using ZFP5-specific probes on sections of 

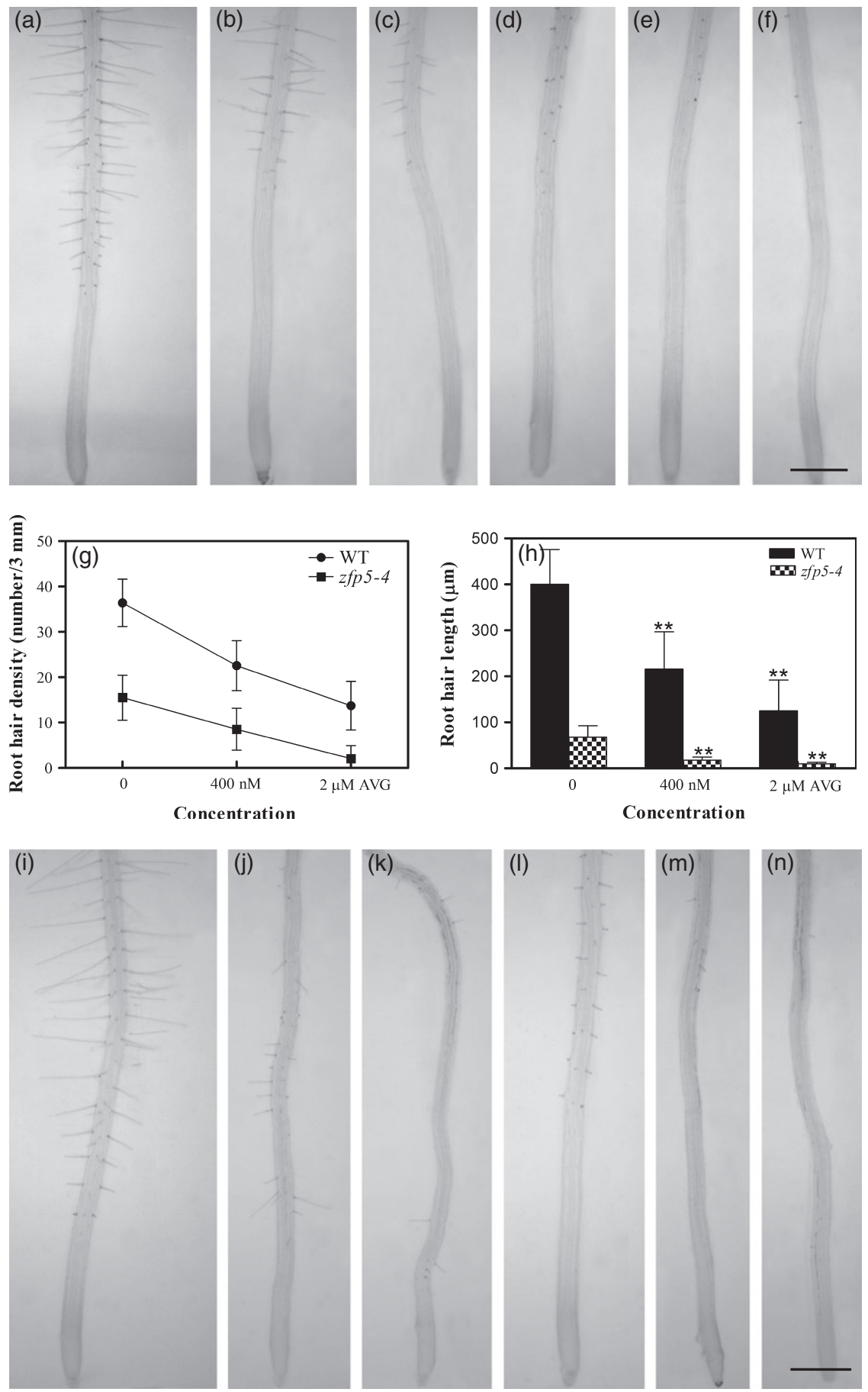

Figure 5. Effect of AVG application on the zfp5-4 mutant and the response of ZFP5 to ethylene signaling.

(a-f) Root hair phenotypes of the wild-type (a-c) and the zfp5-4 mutant (d-f) after AVG treatment: (a,d) control, (b,e) 400 nm AVG, (c,f) $2 \mu \mathrm{m}$ AVG. Scale bar = 500 $\mu$ m. $(\mathrm{g}, \mathrm{h})$ Mean hair density and hair length of the wild-type and zfp5-4 mutant treated with AVG. Values are means \pm standard deviations for at least 20 seedlings. **P< 0.01 for comparison of each genotype with $0 \mu \mathrm{M}$ AVG.

(i-n) Root hair phenotypes of the wild-type (i-k) and the zfp5-4 mutant (I-n) after AVG plus ACC treatment: (i,l) control, (j,m) $1 \mu \mathrm{m}$ ACC and $2 \mu \mathrm{m}$ AVG, (k,n) $1 \mu \mathrm{m}$ ACC and $5 \mu \mathrm{m}$ AVG. Scale bar $=500 \mu \mathrm{m}$.

$(o, p)$ Mean hair density and hair length of the wild-type and zfp5-4 mutant treated with AVG together with ACC. Values are means \pm standard deviations for at least 20 seedlings. ${ }^{*} P<0.01$ for comparison of each genotype with $0 \mu \mathrm{m}$ AVG/ACC.

(q) Transcript levels of ZFP5 in ethylene mutants. Values are means \pm standard deviations $(n=3) . * *<0.01$ for comparison with ZFP5 expression levels in wildtype.

( $\mathrm{r}-\mathrm{t}$ ) Histochemical staining for GUS activity in ZFP5:GUS transgenic plants after exogenous ACC treatment: (r) control, (s) $100 \mathrm{nM}$ ACC, (t) $1 \mu \mathrm{M}$ ACC. Scale bar $=25 \mu \mathrm{m}$.

(u) Detection of ZFP5 protein after ACC treatment by Western blotting. 

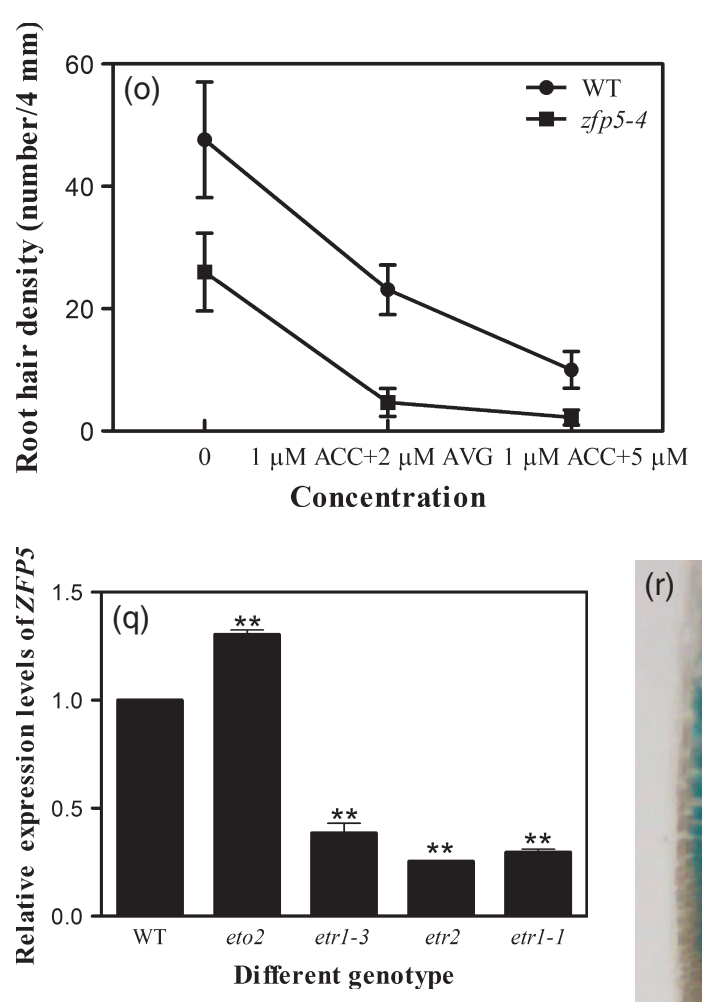

(u)

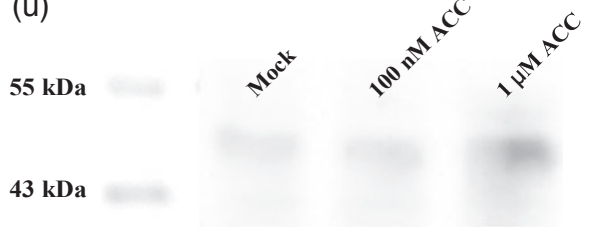

Figure 5. (Continued)

primary roots of 7-day-old seedlings. The in situ hybridization experiment showed that the ZFP5 was mainly expressed in the differentiating zone of the root (Figure 10b,c), particularly in the $\mathrm{H}$ cells of the root epidermis (Figure 10d,e).

\section{DISCUSSION}

We have recently reported that ZFP5 controls trichome initiation through GA signaling (Zhou et al., 2011). Here, we report that ZFP5 also integrates endogenous developmental and exogenous environmental cues to regulate root hair development in Arabidopsis. Analysis of ZFP5 over-expressors and a loss-of-function mutant indicates that ZFP5 plays an important role in controlling both root hair initiation and root hair elongation. ZFP5 also plays roles in mediating the response of root hair development to cytokinin as well as ethylene signals.

\section{ZFP5 acts as a putative $\mathrm{C} 2 \mathrm{H} 2$ zinc finger protein to positively control trichome initiation and root hair development}

The $\mathrm{C} 2 \mathrm{H} 2$-type zinc finger proteins, with 176 members in Arabidopsis thaliana, constitute one of the largest families
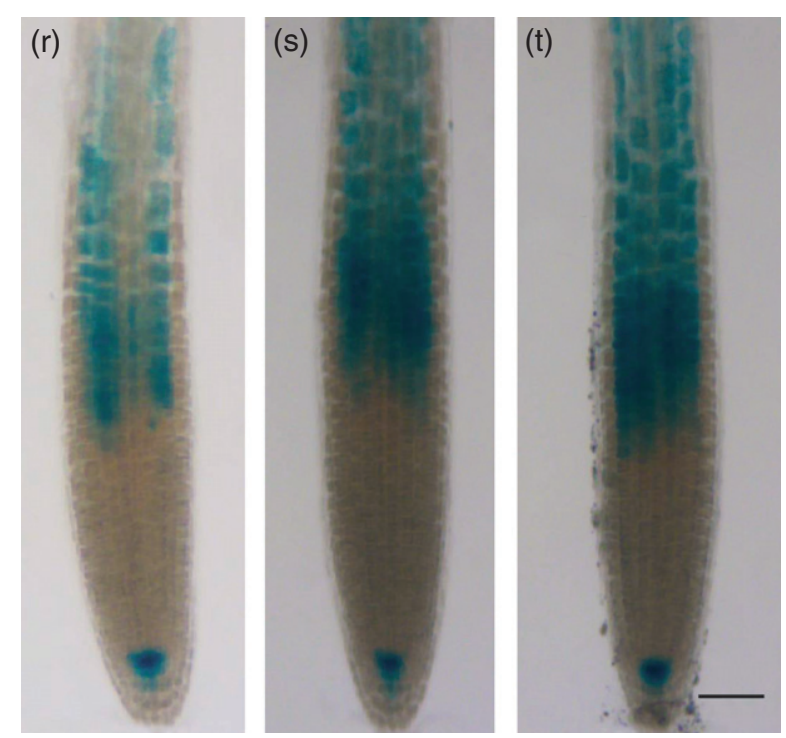

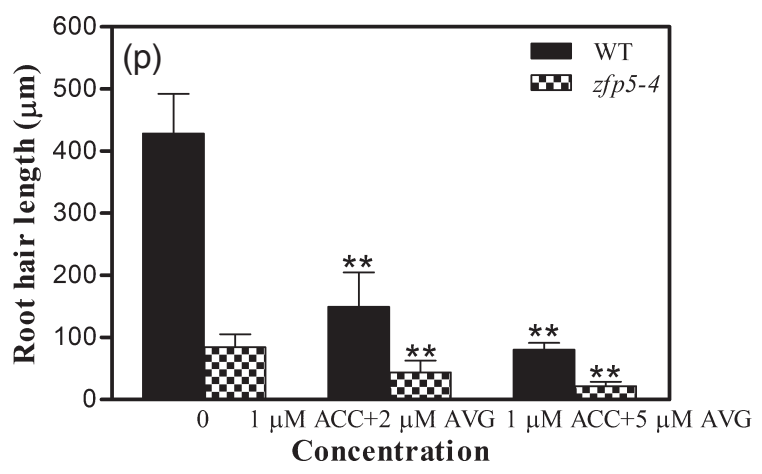

of transcriptional regulators in plants (Laity et al., 2001; Ciftci-Yilmaz and Mittler, 2008). The predicted amino acid sequence of ZFP5 contains a typical $\mathrm{C} 2 \mathrm{H} 2$ domain that is found in the TFIIIA transcription factor class, and also the plant-specific QALGGH motif (Gan et al., 2006, 2007), which are considered as typical of $\mathrm{C} 2 \mathrm{H} 2$-type zinc finger transcription factors (Ciftci-Yilmaz and Mittler, 2008). To date, many studies have shown that $\mathrm{C} 2 \mathrm{H} 2$ zinc finger proteins are required for key cellular processes, including transcriptional regulation, development, pathogen defense and stress responses (Laity et al., 2001; Englbrecht et al., 2004; Ciftci-Yilmaz and Mittler, 2008). Of these, three members of the C1-1i sub-class, named GIS, GIS2 and ZFP8, have been investigated as important regulators of trichome initiation by mediating the gibberellin and cytokinin signals (Gan et al., 2006, 2007). ZFP5 shows high sequence similarity to GIS genes (Gan et al., 2006, 2007). Although ZFP5 is involved in controlling trichome initiation in gibberellin acid signaling, ZFP5 is mainly expressed in the root, particularly the root hair cells (Figure 10a-e). The three GIS family genes are not expressed in the root and 


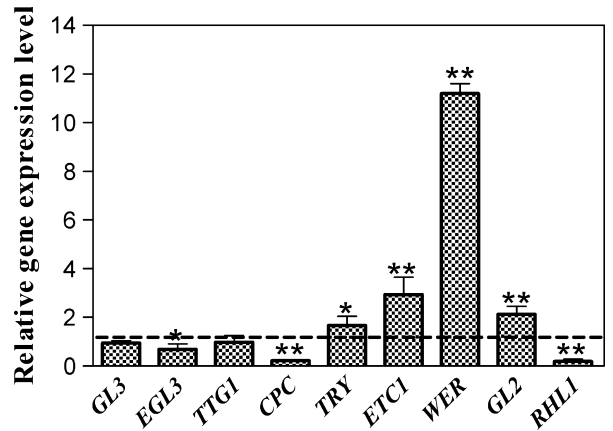

Figure 6. Expression patterns of the key regulators involved in root hair development in the zfp5-4 mutant background. GLABRA 3(GL3), ENHANCER OF GLABRA 3(EGL3), TRANSPARENT TESTA GLABRA 1(TTG1), CAPRICE (CPC), TRIPTYCHON (TRY), ENHANCER OF TRY AND CPC 1(ETC1), WEREWOLF (WER), GLABRA 2 (GL2), ROOT HAIR LESS 1 (RHL1).

Values represent the ratio of gene expression to corresponding wild-type controls. Values are means \pm standard deviations $(n=3)$. ${ }^{*} \mathrm{P}<0.01$ for comparison of each gene expression in wild-type. their mutants have no root hair phenotype, demonstrating the functional divergence of this clade of genes during evolution of plants.

The phenotypes of loss-of-function mutants and overexpressors indicate that ZFP5 promotes root hair development during primary root development (Figure 1a-e). Our analysis of the gene expression and genetic interactions between ZFP5 and genes belonging to the two root initiation complexes WER-GL3/EGL3-TTG1 and CPC-TRY-ETC1 suggests that ZFP5 acts upstream of the CPC-TRY-ETC1 complex and modulates the activity of the complex through a direct transcription mechanism by binding to the $C P C$ promoter (Figure 9). ZFP5 may inhibit formation of the WER-GL3-TTG1 complex by negatively regulating the expression of WER to further restrain the expression of GL2, resulting in inhibition of $\mathrm{N}$ cells (Figure 6). Further studies are required to study the interaction between ZFP5 and WER-GL3-TTG1 at the protein level and to understand
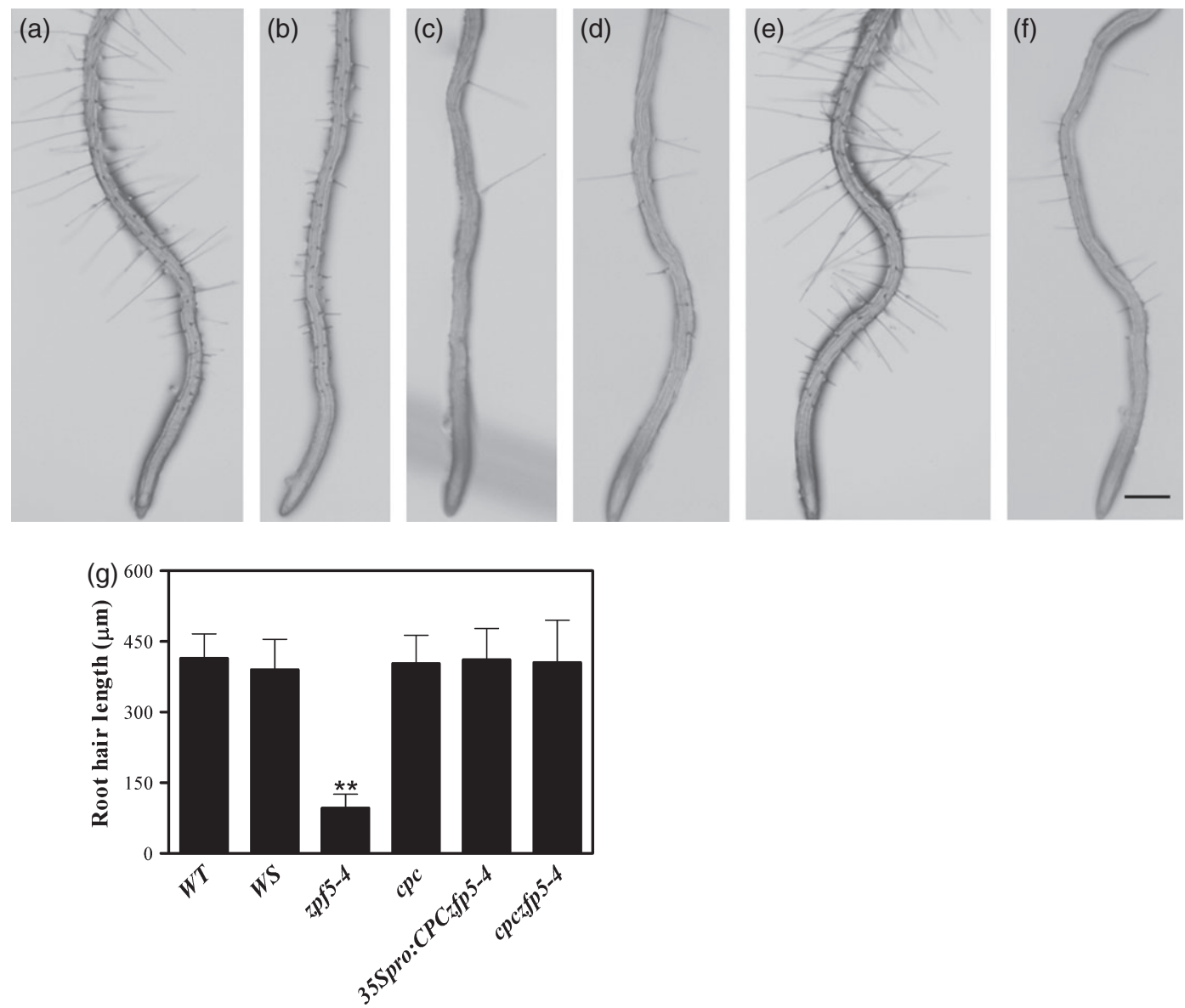

Figure 7. Genetic interaction between ZFP5 and the root hair development regulator CPC.

(a-f) Root hair phenotype on primary roots of wild-type (a), the zfp5-4 mutant (b), the $c p c$ mutant (c), 35S:ZFP5 over-expressors in the $c p c$ mutant (d), 35S:CPC overexpressors in the zfp5-4 mutant (e) and the $c p c$ zfp5-4 double mutant (f). Scale bar $=200 \mu \mathrm{m}$.

(g) Mean root hair length of wild-types Col-0 (WT) and Wassileskija (WS), zfp5-4, cpc, 35S:CPCzfp5-4 and the cpc zfp5-4 double mutant. Values are means \pm standard deviations for at least 20 seedlings. ${ }^{*} P<0.01$ for comparison with wild-type. 

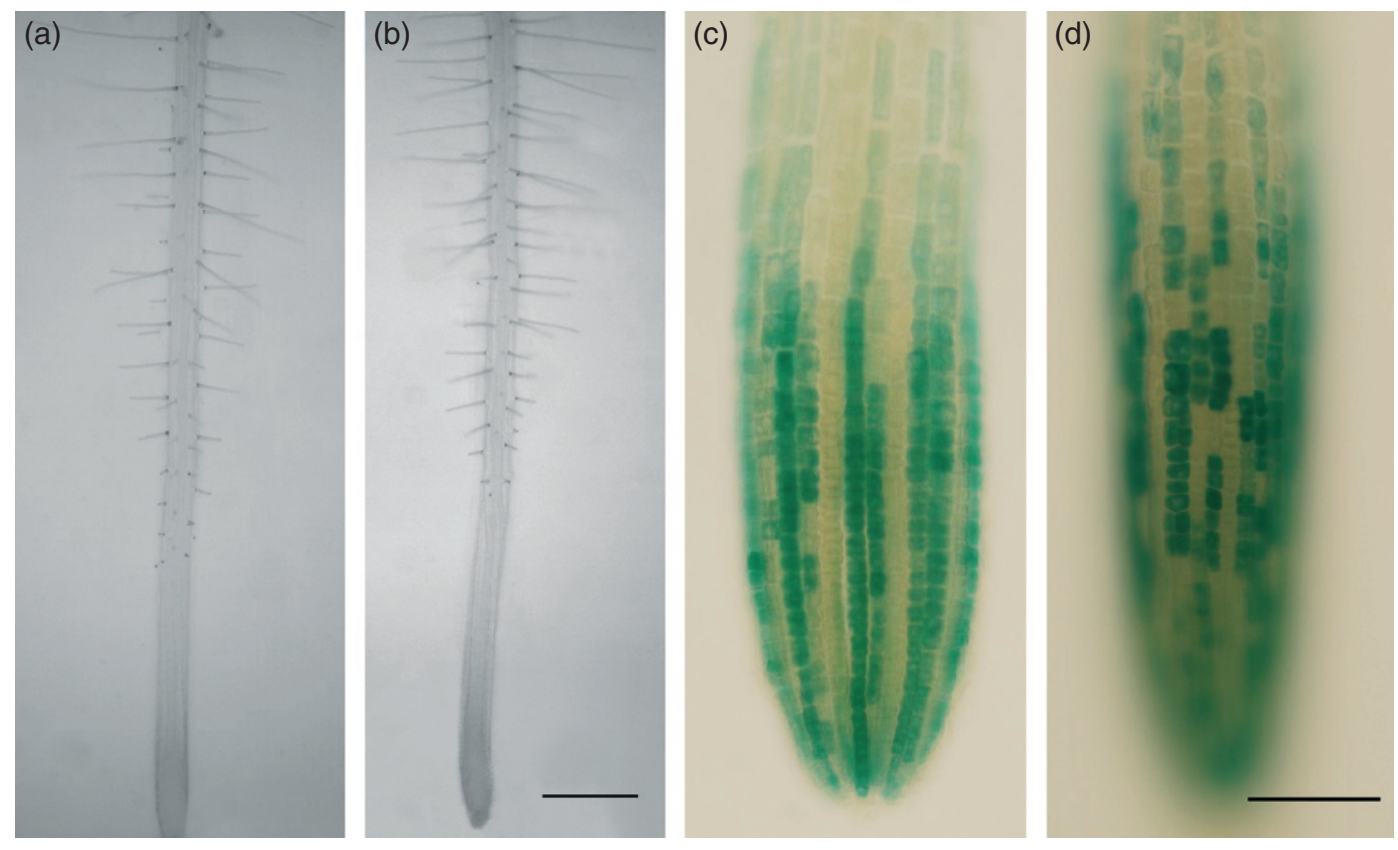

Figure 8. Alteration of the CPC expression pattern by the ZFP5 mutation.

(a,b) Root hair phenotype of CPC:GUS and CPC:GUSzfp5-4 plants. Scale bars $=500 \mu \mathrm{m}$.

(c,d) Histochemical staining for GUS signal in CPC:GUS and CPC:GUSzfp5-4 root epidermis. Scale bars $=50 \mu \mathrm{m}$.

how ZFP5 induces expression of the $\mathrm{N}$ cell-expressed CPC gene.

\section{ZFP5 integrates ethylene and cytokinin signaling to control root hair development}

Although cytokinin promoted both root hair initiation and root hair elongation in wild-type plants (Figure 4a,b,e and Table 2), cytokinin only restored the lower root hair density phenotype but not the shorter root hair phenotype of the zfp5-4 mutant (Figure 4c-e and Table 2). These results indicate that ZFP5 is required in order for cytokinin signaling to regulate root hair elongation. Such a role was further supported by an interaction analysis in 35S:CKX2 transgenic plants, in which the endogenous cytokinin content was lower (Gan et al., 2007). Expression of ZFP5 was suppressed in 35S:CKX2 transgenic plants (Figure 4j), and, consistent with this, both the root hair density and the root hair length were reduced in 35S:CKX2 plants (Figure 4i and Table 1). Although ZFP5 expression was not induced by ethylene at the transcript level, ZFP5 mediates the ethylene signal to regulate root hair development. This is in line with the observation that BA treatment facilitated root hair formation in the mutant. Moreover, the western blotting and GUS staining experiments confirm that ZFP5 responds to ethylene signaling at the protein level (Figure $5 r-u$ ). In addition, we found that cytokinin and ethylene interact to modulate root hair development. The promotion of root hair initiation by cytokinin depends on the fluctuation of ethylene, because the lower root hair density phenotype of zfp5-4 was not rescued by cytokinin when ethylene biosynthesis inhibitor AVG and ethylene signaling transduction inhibitor $\mathrm{AgNO}_{3}$ were added to the medium (Figure S1). Cytokinin control of root hair development through a transcription factor has not been reported previously, and thus our results illustrate a key step of the mechanism of cytokinin control of root hair development.

An interesting finding is that ZFP5 controls root hair development by directly targeting expression of CPC (Figure 9). ZFP5 is predominately expressed in $\mathrm{H}$ cells, but ZFP5 is able to influence expression of the CPC gene in N cells by binding to its promoter region. Possible explanations are that, like CPC protein, ZFP5 also acts as a mobile signal, moving from $\mathrm{H}$ cells to $\mathrm{N}$ cells to activate expression of $\mathrm{CPC}$, or that it binds to CPC when CPC moves from $\mathrm{N}$ cells to $\mathrm{H}$ cells. Further studies are required to verify this possibility.

In summary, we have demonstrated that the $\mathrm{C} 2 \mathrm{H} 2$ zinc finger protein gene ZFP5 is a key gene in regulation of root hair initiation by directly targeting CPC expression in Arabidopsis. Further analyses suggest that ZFP5 is a key regulator, integrating phytohormone signaling to control root hair growth in Arabidopsis. Our identification of the role of ZFP5 provides a first step in elucidation of mechanisms through which plant hormones and environmental signals act together to control root hair development. Further studies of these mechanisms will provide a better understanding of how $\mathrm{C} 2 \mathrm{H} 2$ zinc finger proteins act as the key transcriptional factors perceiving hormone and environmental signals to control root hair development in Arabidopsis. 
(a)

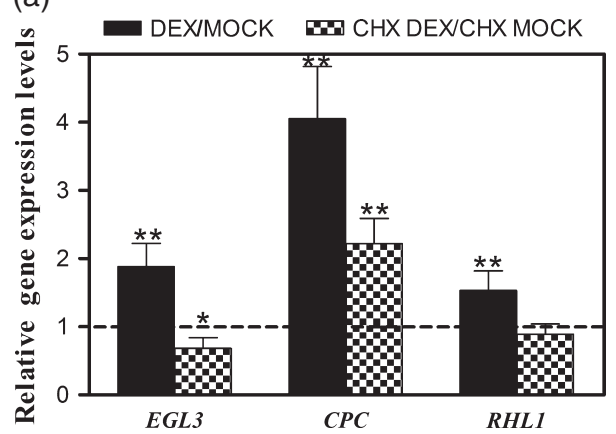

(b)
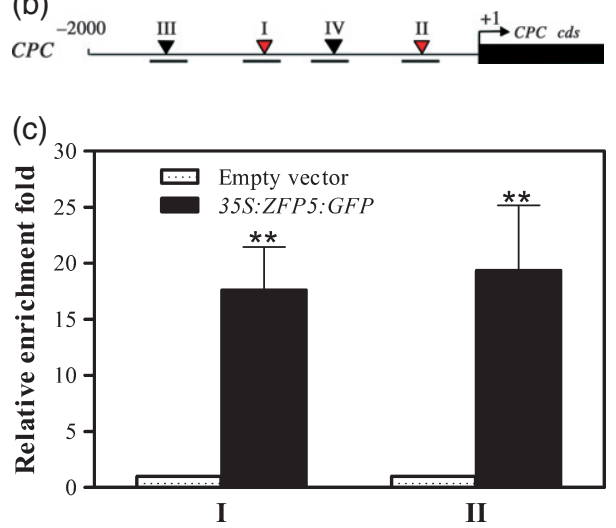

Figure 9. Binding of ZFP5 to the $C P C$ promoter.

(a) Relative expression patterns of EGL3,CPC and RHL 1 in the 35S:ZFP5:GR in the zfp5-4 mutant background after DEX and CHX treatment. Quantitative realtime RT-PCR analysis of RNA from the zfp5-4 mutant harboring 35S:ZFP5:GR treated with $10 \mu \mathrm{m}$ DEX for $4 \mathrm{~h}$ or treated with $10 \mu \mathrm{m}$ DEX and $20 \mu \mathrm{m} \mathrm{CHX} \mathrm{for}$ $4 \mathrm{~h}$. Values are means \pm standard deviations $(n=3) .{ }^{*} \mathrm{P}<0.01$ for comparison with MOCK or CHX MOCK treatment.

(b) Schematic diagram of the CPC promoter region. The red triangles indicate $A[A G / C T] C N A C$ sequences that are presumed to be the zinc finger protein binding site; the black triangles indicate $\mathrm{CpG}$ regions.

(c) ChIP followed by quantitative real-time PCR of CPC genomic fragments in wild-type and 35S:ZFP5:GFP seedlings. Values are means \pm standard deviations $(n=3)$. ${ }^{*} P<0.01$ for comparison with the empty vector control.

\section{EXPERIMENTAL PROCEDURES}

\section{Plant materials and growth conditions}

Arabidopsis thaliana ecotype Col-0 was used as control for most experiments in this study. The zfp5-4 mutant was a transgenic line carrying a T-DNA insertion in the ZFP5 promoter, obtained from the Nottingham Arabidopsis Stock Centre (catalogue number N583960) as described previously (Zhou et al., 2011). Homozygous mutants were selected as described previously (Zhou et al., 2011). The CPC:GUS transgenic line is the same lines as used previously (Kirik et al., 2004a). The cpc zfp5-4 double mutants and CPC:GUSzfp5-4 plants were selected from an $F_{2}$ population by selection on Murashige and Skoog (MS) medium containing kanamycin (50 $\mathrm{mg} \mathrm{L}^{-1}$ ), and confirmed by PCR to ensure both genes were homozygous in these plants.

For all of the genetic transgenic experiments, the constructs in binary vectors were transformed into the Agrobacterium GV3101
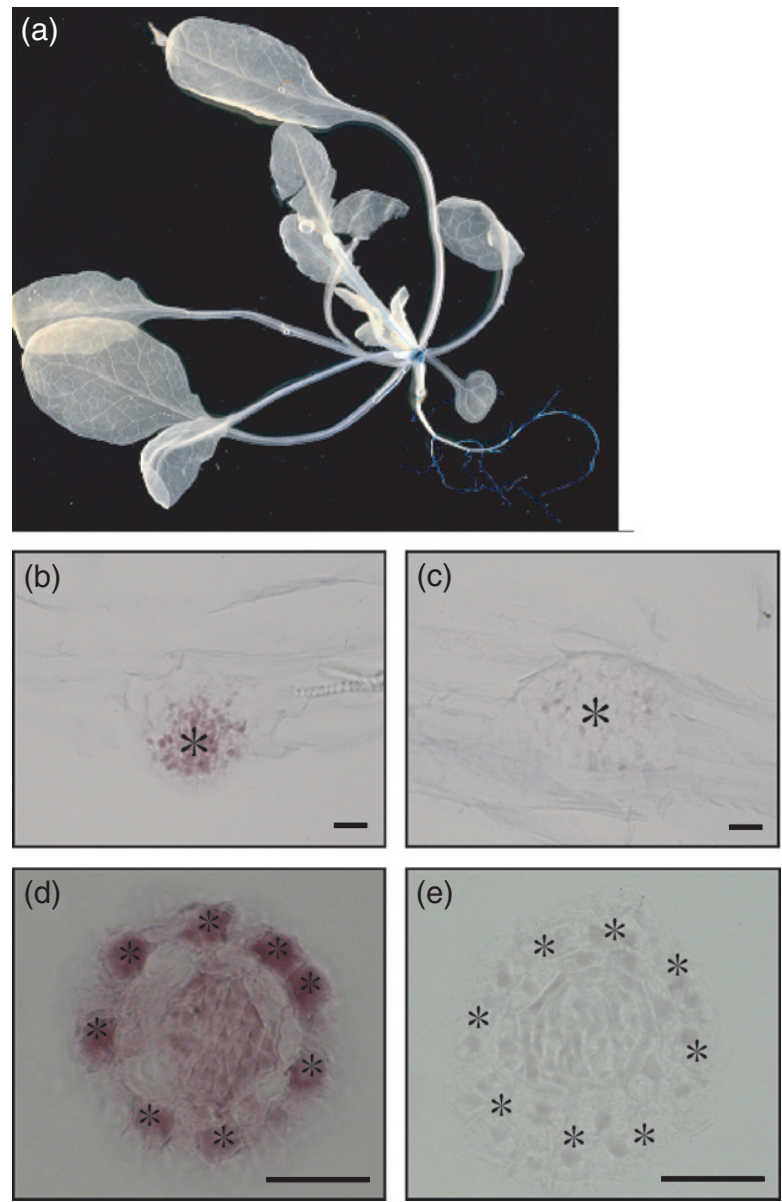

Figure 10. Expression pattern of ZFP5

(a) Histochemical staining for GUS activity in ZFP5:GUS transgenic plants. (b-e) In situ hybridization of ZFP5 probes to root sections. ZFP5 is expressed strongly in the differentiation region of root hairs (b) and the $\mathrm{H}$ cells of the primary root epidermis (d). (c) and (e) show hybridization with a sense probe (control). The asterisks indicate the lateral root primordium in (b) and (e), and $\mathrm{H}$ cells in (d) and (e). Scale bars $=30 \mu \mathrm{m}$.

strain, which was then used to transform Arabidopsis thaliana plants of the appropriate genotype by the floral-dip method (Clough and Bent, 1998). Transgenic seedlings were first selected on MS agar plates with appropriate antibiotics, and then confirmed by PCR using the corresponding primers.

The plants were grown in a controlled growth room under the following conditions: $22 \pm 2{ }^{\circ} \mathrm{C}, 90-120 \mu \mathrm{mol} \mathrm{m}^{-2} \mathrm{sec}^{-1}, 16 \mathrm{~h} \mathrm{light/}$ $8 \mathrm{~h}$ dark, 68-78\% humidity. For in vitro experiments, seeds were surface-sterilized for $10 \mathrm{~min}$ in $30 \%$ bleach solution, washed five times with sterile distilled water, 5 mins each time, plated on MS medium, vernalized at $4^{\circ} \mathrm{C}$ for 2 days in the dark, and then exposed to light.

\section{Root hair measurement}

Root hairs of the primary root of 7-day-old seedlings were visualized using a Leica M295 (Leica Microsystems, http://www.leica microsystems.com/) dissecting microscope, and approximately $4 \mathrm{~mm}$ to the root tip were recorded using a Nikon N995 (Nikon Corporation, http://www.nikon.com/) digital camera. The root length was $4 \mathrm{~mm}$ and the root hair phenotypes were recorded as 
images, and further were used for root hair measurement. The digital images were used directly for root hair length measurement by IMAGEJ (http://rsbweb.nih.gov/ij/) software as described by $\mathrm{Yi}$ et al. (2010). The 20 longest root hairs with obvious ends were measured for each plant; at least 15 seedlings for each genotype were used for each measurement. Measurement of root hair density was performed as described by Schiefelbein and Somerville (1990); the 7-day-old seedlings were viewed using a standard light microscope at medium magnification. The number of root hair cells and the total number of root epidermal cells were counted in a specific area by carefully viewing each cell. For statistical purposes, the same size area was counted from two locations on at least ten roots.

To accurately determine the pattern of the cell types (root hair cells and non-hair cells) in the root epidermis, two regions along the length of a 7-day-old seedling root were selected at random and used for analysis under a standard light microscope at medium magnification. For each region, five contiguous cells from an $\mathrm{H}$ file and five contiguous cells from a neighboring $\mathrm{N}$ file were examined and the numbers were recorded. For each genotype, a total of ten seedling roots were typically analyzed, representing a total of 100 cells ( 5 cells $\times 2$ locations $\times 10$ plants) in the $N$ position and 100 cells in the $\mathrm{H}$ position.

For measurement of the root hair growth rate, a time-lapse strategy was used as described by Szumlanski and Nielsen (2009). The time interval between each measurement was $2 \mathrm{~min}$, and the growth increment was measured using IMAGEJ software.

\section{Hormone treatments}

Benzylaminopurine (BA) (Sigma-Aldrich), the ethylene biosynthesis precursor 1-aminocyclopropane-1-carboxylic acid (ACC) (SigmaAldrich) and the ethylene biosynthesis inhibitor aminoethoxyvinylglycine (AVG) (Sigma-Aldrich, http://www.sigmaaldrich.com/) and ethylene signaling transduction inhibitor $\mathrm{AgNO}_{3}$ were used cytokinin and ethylene applications. The wild-type and zfp5-4 mutant were first cultured on MS medium for 2 days for germination, then transferred to medium containing various concentrations of hormones for another 4 days of growth. The root phenotype was visualized and imaged, and the root hair length, root hair production and patterning were analyzed as described above.

\section{RNA extraction and real-time quantitative PCR}

Total RNA was extracted from Arabidopsis seedlings roots or other organs using TRIzol reagent (Invitrogen, http://www.invitrogen. com/), and cDNA was synthesized from $1.5 \mu \mathrm{g}$ total RNA using M-MLV transcriptase (Promega, http://www.promega.com/) and oligo(dT) ${ }_{18}$ primers in a $25 \mu \mathrm{l}$ reaction according to the manufacturer's instructions. Real-time quantitative PCR was performed as described previously (Zhou et al., 2011). The primers used are listed in Table 3.

\section{Cloning}

For all cloning constructs (35S:ZFP5, ZFP5 RNAi, ZFP5:GUS and 35S:ZFP5:GFP), all target sequences were first inserted into the pENTR-1A vector (Invitrogen) before being recombined into an appropriate destination vector using the Gateway LR reaction (Invitrogen). All destination vectors were obtained from the Vlaams Instituut voor Biotechnologie (Flanders Institute for Biotechnology). pH2GW7 was used for the 35S:ZFP5 construct, pK7GWIWG2(II) for the ZFP5 RNAi construct, pHGWFS7 for the ZFP5:GUS construct, pB7FWG for the 35S:ZFP5:GFP construct, and pGreen for the 35S:ZFP5:GR construct. For all these cloning experiments, genespecific fragments were first PCR-amplified from cDNA (35S:ZFP5,
Table 3 Primers used for quantitative real-time PCR and ChIP analysis

\begin{tabular}{|c|c|}
\hline Gene & Sequence \\
\hline \multirow[t]{2}{*}{ ZFP5 } & LP: 5'-CGGTGAGATGGGTAAGCTGT-3' \\
\hline & RP: 5'-CTCCGGCAAAACCTAGATGA-3' \\
\hline \multirow[t]{2}{*}{$C P C$} & LP: 5'-GAGTTGATCGCCGGAAGGA-3' \\
\hline & RP: 5'-AACGACGCCGTGTTTCATAAG-3' \\
\hline \multirow[t]{2}{*}{$T R Y$} & LP: 5'-AAACAGTGAAGGCTTTGCTGATAAA-3' \\
\hline & RP: 5'-GGACGGTGAGGCTTGGTATG-3' \\
\hline \multirow[t]{2}{*}{ ETC1 } & LP: 5'-CCAACCATTGTTGCCTCTTC- $3^{\prime}$ \\
\hline & RP: 5'-TCATCACCCAAAACCTCTCA-3' \\
\hline \multirow[t]{2}{*}{ GL3 } & LP: 5'-CCAGCAAGATCCGATTATCACA-3' \\
\hline & RP: 5'-ACTGAACATAGGCGCGTAAATCTC-3' \\
\hline \multirow[t]{2}{*}{ EGL3 } & LP: 5'- TGTTCATTACCAAGGCGTGA-3' \\
\hline & RP: 5'-GATGATGATCGCTTCCACCT-3' \\
\hline \multirow[t]{2}{*}{ TTG1 } & LP: 5'-CCGTCTTTGGGAAATTAACGAA-3' \\
\hline & RP: 5'-GCTCGTTTTGCTGTTGTTGAGA-3' \\
\hline \multirow[t]{2}{*}{ GL2 } & LP: 5'-CCCTCTGGATTCTCAATCA-3' \\
\hline & RP: 5'-GACGAGGTTTGTCACGGATT-3' \\
\hline \multirow[t]{2}{*}{ RHL 1} & LP: 5'-ACGGAGGCTATCTTTTGCTGA-3' \\
\hline & RP: 5'-TTGACTAGCGACCATTGCAG-3' \\
\hline \multirow[t]{2}{*}{ ARR5 } & LP: 5'-TTGCGTCCCGAGATGTTAGAT-3' \\
\hline & RP: 5'-TGAGTAACCGCTCGATGAACTTC-3' \\
\hline \multirow[t]{2}{*}{ ACS2 } & LP: 5'-GGTGGCAAACTGAAACTGGT-3' \\
\hline & RP: 5'-TCGATTTCATTGCCCTTTTC-3' \\
\hline \multirow[t]{2}{*}{ WER } & LP: 5'-TGTCAAAGCTCATGGCAAAG-3' \\
\hline & RP: 5'-TCCTCTTCTTGCTCGGTGA-3' \\
\hline \multirow[t]{2}{*}{$P C P C-I$} & LP: 5'-CGTATCTCACCTTCGCACTG-3' \\
\hline & RP: 5'-TGACATGTGGTGGTTAAAGC-3' \\
\hline \multirow[t]{2}{*}{$P C P C-\|$} & LP: 5'-AGGGACATACTGGTCATTTCG-3' \\
\hline & RP: 5'-AATCCTTTGACTTGCGGTTG-3' \\
\hline \multirow[t]{2}{*}{$P C P C-I I I$} & LP: 5'-TCTGTTGTTGTCGGTGTCAA-3' \\
\hline & RP: 5'-ATAAGCCATGGGCCTATTCA-3' \\
\hline \multirow[t]{2}{*}{ PCPC-IV } & LP: 5'-CCAGTAGAGGCACACAACA-3' \\
\hline & RP: 5'-GAGAACAGCAAAACGGGAAA-3' \\
\hline
\end{tabular}

$L P$, left primer; $R P$, right primer; $P C P C$, promoter of $C P C$, primers used for ChIP analysis. ZINC FINGER PROTEIN 5 (ZFP5), CAPRICE (CPC), TRIPTYCHON (TRY), ENHANCER OF TRY AND CPC 1(ETC1), GLABRA 3(GL3), ENHANCER OF GLABRA 3(EGL3), TRANSPARENT TESTA GLABRA 1(TTG1), GLABRA 2 (GL2), ROOT HAIR LESS 1 (RHL1), ARABIDOPSIS RESPONSE REGULATOR 5 (ARR5), ACC SYNTHASE 2 (ACS2), WEREWOLF (WER).

ZFP5 RNAi, 35S:ZFP5:GFP and 35S:ZFP5:GR) or genomic DNA (ZFP5:GUS) using primers containing Sall and Notl restriction sites, and purified using a gel extraction kit (Qiagen, http://www. giagen.com/) before restriction digestion and cloning. The following primers were used: ZFP5 over-expression, 5'-CGGTCGA CATGTCTATAAATCCG-3' and $5^{\prime}$-AAGCGGCCGCTGCCGCATCTCC GGCA-3'; ZFP5 RNAi, 5'-CGGTCGACGAGCCAGCATCGGCTATTAT$3^{\prime}$ and $5^{\prime}$-AAGCGGCCGCAATTTGTTATGCCGCATCTCC-3'. A 1672 bp genomic fragment upstream of the start codon in ZFP5 was amplified using primers $5^{\prime}$-TTGTCGACGGCTTTGATTGCATGAGACA-3' and $5^{\prime}$-TTGCGGCCGCTCGATGGGTTTAATTTGCTT-3' to prepare the ZFP5:GUS constructs.

\section{In situ hybridization and GUS staining}

Non-radioactive in situ hybridization was performed as described previously (Long and Barton, 1998). For synthesis of the antisense and sense ZFP5 RNA probes, a gene-specific fragment was amplified 
using the same primers as for generating the ZFP5 RNAi constructs (see above) and cloned into the pGEM-T Easy vector (Promega). The resulting plasmid served as a template for in vitro transcription, which was performed using the DIG RNA labeling kit (Roche Molecular Biochemicals, http://www.roche.com/).

The plant lines that include ZFP5:GUS constructs in the wild-type background were first selected using hygromycin, then confirmed by PCR for screening homozygous lines. The $T_{3}$ generation plants were used for analysis by histochemical staining, and viewed under a microscope.

\section{Protein analysis}

Seven-day-old 35S:ZFP5:GFP plants were treated with mock solution, $100 \mathrm{~nm}$ or $1 \mathrm{~m} \mathrm{ACC}$. After $4 \mathrm{~h}$, approximately $0.2 \mathrm{~g}$ root were harvested, and total protein was extracted using extraction buffer $(0.25 \mathrm{~m} \mathrm{NaCl}, 1 \%$ SDS, $1 \% \beta$-mercaptoethanol, $0.05 \mathrm{M}$ PBS $\mathrm{pH}$ 7.5, $1 \mathrm{~mm}$ phenylmethanesulfonyl fluoride). $2 \times$ SDS-PAGE sample buffer $(0.125 \mathrm{~m}$ Tris $\mathrm{pH} 6.8,4 \%$ SDS, $20 \%$ glycerol, $2 \%$ $\beta$-mercaptoethanol and $0.02 \%$ bromophenol blue) was added, and the mixture was boiled for $10 \mathrm{~min}$, cooled on ice for $5 \mathrm{~min}$, and centrifuged at $12000 \mathrm{~g}$ at $4^{\circ} \mathrm{C}$ for $2 \mathrm{~min}$ as described by Deng et al. (2007). The supernatants were resolved via $12 \%$ SDS-PAGE, and the proteins were transferred onto Immobilon-NC nitrocellulose membranes (Millipore, http://www.millipore.com/). Anti-GPF polyclonal antibodies (Abmart, http://www.ab-mart.com/) were used for immunoblotting. Proteins were detected using a SuperSignal West Pico chemiluminescence kit (Pierce, http://www. piercenet.com/).

\section{Dexamethasone (DEX) treatment}

DEX treatment and sample collection were performed as described by $\mathrm{Yi}$ et al. (2010). The concentration of DEX and cycloheximide (CHX) were performed as described by Zhou et al. (2011). UBQ10 transcripts were used as an endogenous control to normalize expression of the other genes. At least three independent quantitative RT-PCR experiments were performed.

\section{Chromatin immunoprecipitation (ChIP)}

ChIP experiments were performed as described previously ( $\mathrm{Yu}$ et al., 2010). Approximately $3 \mathrm{~g}$ of root tissue from 7-day-old 35S:ZFP5:GFP and control plants were harvested and fixed using $15.4 \mathrm{ml}$ fixation buffer $(0.4 \mathrm{~m}$ sucrose, $10 \mathrm{~mm}$ Tris $\mathrm{pH} 8.0,1 \mathrm{~mm}$ EDTA pH 7.5, $1 \mathrm{~mm}$ phenylmethanesulfonyl fluoride, $1 \%$ formaldehyde) under vacuum for $10 \mathrm{~min}$. After fixation, the materials were ground with liquid nitrogen, and the resulting powder was transferred to $10 \mathrm{ml}$ extraction buffer $(0.4 \mathrm{M}$ sucrose, $10 \mathrm{~mm}$ Tris/ $\mathrm{HCl} \mathrm{pH}$ 8.0, $10 \mathrm{~mm} \mathrm{MgCl} 2,5 \mathrm{~mm}$ mercaptoethanol, $0.1 \mathrm{~mm}$ phenylmethanesulfonyl fluoride, $1 \times$ protease inhibitor, Basel, Switzerland), gently mixed and kept at $4^{\circ} \mathrm{C}$ until the solution was homogenous, then rotated at $1503 \mathrm{~g}$ at $4^{\circ} \mathrm{C}$ for $20 \mathrm{~min}$. The solution was discarded and the pellet was resuspended in lysis buffer $(50 \mathrm{~mm}$ HEPES pH 7.5, $150 \mathrm{~mm} \mathrm{NaCl}, 1 \mathrm{~mm}$ EDTA, $1 \%$ Triton X-100, 0.1\% deoxycholate sodium, $0.1 \%$ SDS), then sonicated using a JY96-II ultrasonic cell disruptor (Output 3, $6 \times 10 \mathrm{sec}$; Ningbo Scientz Biotechnology Co.,Ltd, http://www. scientz.com/en/). The solution was then divided into three parts: one was saved as input DNA, and other two parts were incubated with either anti-GFP antibody (Abmart) or an anti-MYC antibody (Abmart), the latter being used as a negative control. After affinity immunoprecipitation, the precipitated DNA samples were purified. The relative concentrations of the DNA fragments were analyzed by quantitative real-time PCR in triplicate, using the $\beta$-tubulin2 gene promoter as the reference, and fold enrichment was calculated as described previously (Jun et al., 2010; Yu et al. 2010). The experiment was repeated twice with similar results The primers used are listed in Table 3.

\section{ACCESSION NUMBERS}

The Arabidopsis Genome Initiative or GenBank/EMBL database accession numbers for the genes referred to in this appear are given in parentheses: ZFP5 (At1g10480), GL3 (At5g41315), EGL3 (At1g63650), TTG1 (At5g24520), CPC (At2g46410), TRY (At5g53200), ETC1 (At1g01380), GL2 (At1g79840), WER (At5g14750), AtHAK5 (At4g13420), ARR5 (At3g48100), ACS2 (At1g01480) and UBQ10 (At4g05320).

\section{ACKNOWLEDGEMENTS}

The research was supported by Zhejiang Provincial Natural Science Foundation of China (grant number Z31100041), the National Natural Science Foundation of China (grant numbers 30970167 and 31000093), the International Scientific and Technological Cooperation Project of the Ministry of Science and Technology of China (grant number 2010DFA34430), the US National Science Foundation (grant number IOS-1121602), the Zhejiang Qianjiang Talent Program (grant number 2010R10084) and the PhD Programs Foundation of the Ministry of Education of China (grant number 20090101110097).

\section{SUPPORTING INFORMATION}

Additional Supporting Information may be found in the online version of this article:

Figure S1. Effects of $\mathrm{AVG}$ and $\mathrm{AgNO}_{3}$ on induction of root hair density by cytokinin.

Please note: As a service to our authors and readers, this journal provides supporting information supplied by the authors. Such materials are peer-reviewed and may be re-organized for online delivery, but are not copy-edited or typeset. Technical support issues arising from supporting information (other than missing files) should be addressed to the authors.

\section{REFERENCES}

Bernhardt, C., Lee, M.M., Gonzalez, A., Zhang, F., Lloyd, A. and Schiefelbein J. (2003) The bHLH genes GLABRA3 (GL3) and ENHANCER OF GLABRA3 (EGL3) specify epidermal cell fate in the Arabidopsis root. Development, 130, 6431-6439.

Bernhardt, C., Zhao, M., Gonzalez, A., Lloyd, A. and Schiefelbein, J. (2005) The bHLH genes GL3 and EGL3 participate in an intercellular regulatory circuit that controls cell patterning in the Arabidopsis root epidermis. Development, 132, 291-298.

Bishopp, A., Help, H., Ei-Showk, S., Weijers, D., Scheres, B., Friml, J., Benkova, E., Mähönen, A.P. and Helariutta, Y. (2011) A mutually inhibitory interaction between auxin and cytokinin specifies vascular pattern in roots. Curr. Biol. 21, 917-926.

Bucio, J., Ramírez, A. and Estrella, L. (2003) The role of nutrient availability in regulating root architecture. Curr. Opin. Plant Biol. 6, 280-287.

Ciftci-Yilmaz, S. and Mittler, R. (2008) The zinc finger network of plants. Cell. Mol. Life Sci. 65, 1150-1160.

Clough, S.J. and Bent, A.F. (1998) Floral dip: a simplified method for Agrobacterium- mediated transformation of Arabidopsis thaliana. Plant J. 16, 735-743.

Costa, S. and Shaw, P. (2006) Chromatin organization and cell fate switch respond to positional information in Arabidopsis. Nature, 439 493-496.

Deng, Z., Zhang, X., Tang, W. et al. (2007) A proteomics study of brassinos teroid response in Arabidopsis. Mol. Cell. Proteomics 6, 2058-2071.

Desbrosses, G., Josefsson, C., Rigas, S., Hatzopoulos, P. and Dolan, L. (2003) AKT1 and TRH1 are required during root hair elongation in Arabidopsis. J. Exp. Bot. 54, 781-788. 
Englbrecht, C.C., Schoof, H. and Bohm, S. (2004) Conservation, diversification and expansion of $\mathrm{C} 2 \mathrm{H} 2$ zinc finger proteins in the Arabidopsis thaliana genome. BMC Genomics, 5, 39.

Esch, J.J., Chen, M.A., Hillestad, M. and Marks, M.D. (2004) Comparison of TRY and the closely related At1g01380 gene in controlling Arabidopsis trichome patterning. Plant J. 40, 860-869.

Galway, M.E., Masucci, J.D., Lloyd, A.M., Walbot, V., Davis, R.W. and Schiefelbein, J.W. (1994) The TTG gene is required to specify epidermal cell fate and cell patterning in the Arabidopsis root. Dev. Biol. 166, 740-754.

Gan, Y., Kumimoto, R., Liu, C., Ratcliffe, O., Yu, H. and Broun, P. (2006) GLABROUS INFLORESCENCE STEMS modulates the regulation by gibberellins of epidermal differentiation and shoot maturation in Arabidopsis. Plant Cell, 18, 1383-1395.

Gan, Y., Liu, C., Yu, H. and Broun, P. (2007) Integration of cytokinin and gibberellin signaling by Arabidopsis transcription factors GIS, ZFP8 and GIS2 in the regulation of epidermal cell fate. Development, 134, 20732081.

Gilroy, S. and Jones, D.L. (2000) Through forms to function: root hair development and nutrient uptake. Trends Plant Sci. 5, 56-60.

Guimil, S. and Dunand, C. (2006) Patterning of Arabidopsis epidermal cells: epigenetic factors regulate the complex epidermal cell fate pathway Trends Plant Sci. 11, 601-609.

Ishida, T., Kurata, T., Okada, K. and Wada, T. (2008) A genetic regulatory network in the development of trichomes and root hairs. Annu. Rev. Plant Biol. 59, 365-386.

Jones, R., Kramer, M., Knox, K., Swarup, R., Bennett, M., Lazarus, C., Leyser, H. and Grierson, C. (2009) Auxin transport through non-hair cells sustains root-hair development. Nat. Cell Biol. 11, 78-84.

Jun, J.H., Ha, C.M. and Fletcher, J.C. (2010) BLADE-ON-PETIOLE1 coordinates organ determinacy and axial polarity in Arabidopsis by directly activating ASYMMETRIC LEAVES2. Plant Cell, 22, 62-76.

Jung, J.Y., Shin, R. and Schachtman, D.P. (2009) Ethylene mediates response and tolerance to potassium deprivation in Arabidopsis. Plant Cell, 21, 607621.

Kim, E.J., Kwak, J.M., Uozumi, N. and Schroeder, J.I. (1998) AtKUP1: an Arabidopsis gene encoding high-affinity potassium transport activity. Plant Cell, 10, 51-62.

Kirik, V., Simon, M., Hülskamp, M. and Schiefelbein, J. (2004a) The ENHANCER OF TRY AND CPC1 gene acts redundantly with TRIPTYCHON and CAPRICE in trichome and root hair cell patterning in Arabidopsis. Dev. Biol. 268, 506-513.

Kirik, V., Simon, M., Wester, K., Schiefelbein, J. and Hülskamp, M. (2004b) ENHANCER of TRY and CPC2 (ETC2) reveals redundancy in the regionspecific control of trichome development of Arabidopsis. Plant Mol. Biol. 55, 389-398.

Kubo, K., Sakamoto, A., Kobayashi, A., Rybka, Z., Kanno, Y., Nakagawa, H. and Takatsuji, H. (1998) Cys2/His2 zincfinger protein family of petunia: evolution and general mechanism of target-sequence recognition. Nucleic Acids Res. 26, 608-615.

Kurata, T., Ishida, T., Kawabata-Awai, C. et al. (2005) Cell-to-cell movement of the CAPRICE protein in Arabidopsis root epidermal cell differentiation. Development, 132, 5387-5398.

Kushwah, S., Jones, A.M. and Laxmi, A. (2011) Cytokinin interplay with ethylene, auxin and glucose signalling controls Arabidopsis seedling root directional growth. Plant Physiol. 156, 1851-1866.

Laity, J.H., Lee, B.M. and Wright, P.E. (2001) Zinc finger proteins: new insights into structural and functional diversity. Curr. Opin. Struct. Biol. 11, 39-46.

Lee, M.M. and Schiefelbein, J. (1999) WEREWOLF, a MYB-related protein in Arabidopsis, is a position-dependent regulator of epidermal cell patterning. Cell, 99, 473-483.

Long, J.A. and Barton, M.K. (1998) The development of apical embryonic pattern in Arabidopsis. Development, 125, 3027-3035.

López-Bucio, J., Hernández-Abreu, E., Sánchez-Calderón, L., Nieto-Jacobo, M.F., Simpson, J. and Herrera-Estrella, L. (2002) Phosphate availability alters architecture and causes changes in hormone sensitivity in the Arabidopsis root system. Plant Physiol. 129, 244-256.

Masucci, J.D., Rerie, W.G., Foreman, D.R., Zhang, M., Galway, M.E., Marks, M.D. and Schifelbein, J.W. (1996) The homeobox gene GLABRA2 is required for position-dependent cell differentiation in the root epidermis of Arabidopsis thaliana. Development, 122, 1253-1260.
Müller, M. and Schmidt, W. (2004) Environmentally induced plasticity of root hair development in Arabidopsis. Plant Physiol. 134, 409-419.

Muraro, D., Byrne, H., King, J., Vo $\beta$, U., Kieber, J. and Bennett, M. (2011) The influence of cytokinin-auxin cross-regulation on cell fate determination in Arabidopsis thaliana root development. J. Theor. Biol. 283, 152-167.

Pesch, M. and Hülskamp, M. (2004) Creating a two-dimensional pattern de novo during Arabidopsis trichome and root hair initiation. Curr. Opin Genet. Dev. 14, 422-427.

Rahman, A., Hosokawa, S., Oono, Y., Amakawa, T., Goto, N. and Tsurumi, S. (2002) Auxin and ethylene response interactions during Arabidopsis root hair development dissected by auxin influx modulators. Plant Physiol. 130, 1908-1917.

Rigas, S., Debrosses, G., Haralampidis, K., Vicente-Agullo, F., Feldmann, K.A., Grabov, A., Dolan, L. and Hatzopoulos, P. (2001) TRH1 encodes a potassium transporter required for tip growth in Arabidopsis root hairs. Plant Cell, 13, 139-151.

Sakai, H., Medrano, L.J. and Meyerowitz, E.M. (1995) Role of SUPERMAN in maintaining Arabidopsis floral whorl boundaries. Nature, 378, 199-203.

Samalova, M., Brzobohaty, B. and Moore, I. (2005) pOp6/LhGR: a stringently regulated and highly responsive dexamethasone-inducible gene expression system for tobacco. Plant J. 41, 919-935.

Schellmann, S., Schnittger, A., Kirik, V., Wada, T., Okada, K., Beermann, A., Thumfahrt, J., Jurgens, G. and Hülskamp, M. (2002) TRIPTYCHON and CAPRICE mediate lateral inhibition during trichome and root hair patterning in Arabidopsis. EMBO J. 21, 5036-5046.

Schiefelbein, J. and Lee, M.M. (2006) A novel regulatory circuit specifies cell fate in the Arabidopsis root epidermis. Physiol. Plant. 126, 503-510.

Schiefelbein, J.W. and Somerville, C. (1990) Genetic control or root hair development in Arabidopsis thaliana. Plant Cell, 2, 235-243.

Schiefelbein, J., Kwak, S., Wieckowski, Y., Barron, C. and Bruex, A. (2009) The gene regulatory network for root epidermal cell-type pattern formation in Arabidopsis. J. Exp. Bot. 60, 1515-1521.

Schmidt, W. and Schikora, A. (2001) Different pathways are involved in phosphate and iron stress-induced alterations of root epidermal cell development. Plant Physiol. 125, 2078-2084.

Seifert, G.J., Barber, C., Wells, B., Dolan, L. and Roberts, K. (2002) Galactose biosynthesis in Arabidopsis: genetic evidence for substrate channeling from UDP-D-galactose into cell wall polymers. Curr. Biol. 12, 1840-1845.

Simon, M., Lee, M.M., Lin, Y., Gish, L. and Schiefelbein, J. (2007) Distinct and overlapping roles of single-repeat MYB genes in root epidermal patterning Dev. Biol. 311, 4566-4578.

Strader, L.C., Chen, G.L. and Bartel, B. (2010) Ethylene directs auxin to control root cell expansion. Plant J. 64, 874-884.

Szumlanski, A.L. and Nielsen, E. (2009) The Rab GTPase RabA4d regulates pollen tube tip growth in Arabidopsis thaliana. Plant Cell, 21, 526-544.

Takeda, S., Gapper, C., Kaya, H., Bell, E., Kuchitsu, K. and Dolan, L. (2008) Local positive feedback regulation determines cell shape in root hair cells. Science, 319, 1241-1244.

Tanimoto, M., Roberts, K. and Dolan, L. (1995) Ethylene is a positive regulator of root hair development in Arabidopsis thaliana. Plant J. 8, 943-948.

Tominaga, R., Iwata, M., Sano, R., Inoue, K., Okada, K. and Wada, T. (2008) Arabidopsis CAPRICE-LIKE MYB 3 (CPL3) controls endoreduplication and flowering development in addition to trichome and root hair formation. Development, 135, 1335-1345.

Tominaga-Wada, R., Ishida, T. and Wada, T. (2011) New insights into the mechanism of development of Arabidopsis root hairs and trichomes. Int. Rev. Cell. Mol. Biol. 286, 67-106.

Wada, T., Tachibana, T., Shimura, Y. and Okada, K. (1997) Epidermal cell differentiation in Arabidopsis determined by a Myb homolog, CPC Science, 277, 1113-1116

Wada, T., Kurata, T., Tominaga, R., Koshino-Kimura, Y., Tachibana, T., Goto K., Marks, M.D., Shimura, Y. and Okada, K. (2002) Role of a positive regulator of root hair development, CAPRICE, in Arabidopsis root epidermal cell differentiation. Development, 129, 5409-5419.

Werner, T. and Schmülling, T. (2009) Cytokinin action in plant development. Curr. Opin. Plant Biol. 12, 527-538.

Wymer, C.L., Bibikova, T.N. and Gilroy, S. (1997) Cytoplasmic free calcium distributions during the development of root hairs of Arabidopsis thaliana. Plant J. 12, 427-439. 
490 Lijun An et al.

Yi, K., Menand, B., Bell, E. and Dolan, L. (2010) A basic helix-loop-helix transcription factor controls cell growth and size in root hairs. Nat. Genet. 42 264-267.

Yu, N., Cai, W.J., Wang, S.C., Shan, C.M., Wang, L.J. and Chen, X.Y. (2010) Temporal control of trichome distribution by microRNA156-targeted SPL genes in Arabidopsis thaliana. Plant Cell, 22, 2322-2335.

Zhang, W.J., To, J.P.C., Cheng, C.Y., Schaller, G.E. and Kieber, J. (2011) TypeA response regulators are required for proper root apical meristem func- tion through the post-transcriptional regulation of PIN auxin efflux carriers. Plant J. 68, 1-10.

Zhou, Z.J., An, L.J., Sun, L.L., Zhu, S.J., Xi, W.Y., Broun, P., Yu, H. and Gan, Y.B. (2011) Zinc Finger Protein 5 (ZFP5) is required for the control of trichome initiation by acting upstream of ZFP8 in Arabidopsis thaliana. Plant Physiol. 157, 673-682. 